Monatsschr Kinderheilkd 2014 [Suppl 2]

162:228-245

DOI 10.1007/s00112-014-3207-5

๑) Springer-Verlag Berlin Heidelberg 2014

\section{Abstracts der 22. Jahrestagung der Deutschen Gesellschaft für Pädiatrische Infektiologie (DGPI)}

\section{Wissenschaftliche Leitung}

PD Dr. med. Roswitha Bruns, Greifswald

\section{Vorträge}

\author{
Infektionsdiagnostik
}

\section{DGPI-SY-ID-2}

Biomarker zur Diagnostik der viralen und bakteriellen Meningitis

Tenenbaum T.'

'Klinik für Kinder - und Jugendmedizin, Pädiatrische Infektiologie und Pneumologie, Mannheim

Einleitung. Innerhalb der letzten Jahre hat die Bedeutung neuer Biomarker in der Infektionsdiagnostik zugenommen. Die Nützlichkeit dieser neuen diagnostischen Tools wird aber intensiv diskutiert.

Methoden. In dem Übersichtsvortrag soll die wissenschaftliche Wertigkeit neuer Biomarker für die Meningitisdiagnostik dargestellt und diskutiert werden.

Ergebnisse. Der routinemäßige Einsatz von Procalcitonin (PCT) bei v. a. Meningitis bei Kindern über 3 Monaten erscheint zur Differenzierung zwischen viraler und akut bakterieller Meningitis vielversprechend. Unter den neuen Biomarkern ist die wissenschaftliche Datenlage für das PCT mit am besten.

Schlussfolgerung. Der zukünftige routinemäßige Einsatz von Biomarkern wie dem PCT wird letztlich davon abhängen, wie gut eine bakterielle Meningitis ausgeschlossen werden kann. Weitere große prospektive Studien mit sehr sensitiven PCT-Testverfahren würden hierfür notwendig sein.

\section{Neues auf dem Gebiet der Pathogeneseforschung}

\section{DGPI-SY-NP-1}

Varizella-zoster-Virus(VZV)-spezifische Immunität bei solider Organtransplantation oder Autoimmun-Arthritis unter immunsuppressiver Therapie

\section{Prelog M. ${ }^{1}$}

'Universitäts-Kinderklinik Würzburg, Pädiatrische Rheumatologie, Spezielle Immunologie und Osteologie, Würzburg

Hintergrund. Disseminierte primäre Varizella-zoster-Virus (VZV) Infektionen oder Reaktivierung der latenten Infektion in Form von Her- pes zoster können zu einer erhöhten Morbidität und Mortalität bei immunsupprimierten Patienten nach solider Organtransplantation (SOT) oder mit rheumatischen Erkrankungen, wie z. B. der juvenilen idiopathischen Arthritis (JIA) und der rheumatoiden Arthritis (RA), beitragen. Die Immunität gegen VZV wird durch das humorale (Antikörper) und das zelluläre Immunsystem (spezifische T-Zellen) vermittelt.

Ziel und Methodik. Ziel der Untersuchung war es daher, die spezifische Antikörper-Antwort an Hand der Konzentrationen von IgG-anti-VZV und deren Bindungsfähigkeit (Avidität) bei Patienten nach SOT $(\mathrm{n}=42)$ oder mit RA $(n=56)$ oder JIA $(n=75)$ mittels adaptierter ELISA-Verfahren zu untersuchen. Zusätzlich wurden die VZV-spezifischen T-Zellen mittels ELISPOT analysiert.

Ergebnisse. SOT-Patienten zeigten niedrigere Aviditäten (relativer Aviditätsindex RAI 78,8\%) bei sonst vergleichbaren Antikörperkonzentrationen zu altersgleichen Kontrollpersonen (RAI 89,3\%). RA und JIA wiesen keinen Unterschied zu den altersgleichen Kontrollpersonen bezüglich IgG-anti-VZV Konzentrationen oder Aviditäten auf. Signifikant niedrigere Spot-forming-units im ELISPOT zeigten SOT und RA Patienten im Vergleich zu gesunden Erwachsenen, während JIA-Patienten vergleichbare Werte zu gesunden Kindern zeigten.

Diskussion. Eine verminderte Avidität bei normalen IgG-anti-VZV Konzentrationen und eine erniedrigte zelluläre Reaktivität gegen VZV sollte bei immunsupprimierten Patienten bei der Evaluation der VZVspezifischen Immunität berücksichtigt werden.

\section{DGPI-SY-NP-4}

Inflammasom-Aktivierung durch Gruppe-A-Streptokokken

Toepfner N. ${ }^{1}$, Luksch H. ${ }^{1}$, Rösen-Wolff A. ${ }^{1}$, Berner R. ${ }^{1}$

${ }^{1}$ Klinik und Poliklinik für Kinder- und Jugendmedizin, Universitätsklinikum Carl Gustav Carus, Technische Universität Dresden, Dresden

Gruppe-A-Streptokokken (GAS) zählen weltweit zu den häufigsten bakteriellen Krankheitserregern im Kindes- und Jugendalter. GAS-Infektionen können zu lokalen und generalisierten Entzündungsprozessen führen. Inflammasome gehören zu den intrazellulären Erkennungsmechanismen körperfremder und körpereigener Gefahrensignale. Neben den membranständigen Toll-like-Rezeptoren sind Inflammasome Teil des angeborenen Immunsystems und nehmen eine Schlüsselposition in der angeborenen Immunabwehr bakterieller Pathogene ein. GAS können über das $\mathrm{NLRP}_{3}$-Inflammasom die Caspase-1 aktivieren und die Sekretion pro-inflammatorischer Zytokine stimulieren. Im Vortrag wird die Inflammasom-Aktivierung im Rahmen phänotypisch unterschiedlicher GAS-Infektionen in Korrelation zum GAS-spezifischen molekularen Virulenzprofil vorgestellt. 


\section{Problematik multiresistenter Erreger}

\section{DGPI-SY-PM-1}

Immunologisch selbstständig werden - Entwicklung des Immunsystems nach der Geburt

Gille C.

'Universitätsklinikum Tübingen, Neonatologie, Tübingen

Die fetomaternale Immuntoleranz ist Voraussetzung für eine erfolg reiche Schwangerschaft. Immunreaktionen, die eine Abstoßung verursachen, sind intrauterin abgeschwächt. Postpartal besteht eine erhöhte Infektanfälligkeit. Auf der anderen Seite sind inflammatorische Gewebsschädigungen z. B. im Rahmen der Bronchopulmonalen Dysplasie und der Periventrikulären Leukomalazie nur beim Neu- und Frühgeborenen zu finden. Quantitative Unterschiede im sich adaptierenden im Vergleich zum adulten Immunsystem finden sich in verschiedenen Effektorsystemen, wie z. B. die verminderte Granulozytenreserve, Antikörperspiegel, veränderte Defensin-Spiegel auf der Haut und im Darm das fehlende immunologische Gedächtnis und die Expansion von myeloiden Suppressorzellen (MDSC) im Nabelschnurblut. Qualitativ ist unter anderem die Expression von pattern-recognition Rezeptoren auf angeborenen Immunzellen, die Signalübermittlung antigenpräsentierender Zellen an T-Zellen, die T-Zell-Aktivierbarkeit aber auch das verminderte Absterben von aktivierten Immunzellen zu nennen. Neuere Erkenntnisse zeigen, dass der veränderte Funktionszustand des neonatalen Immunsystems nicht nur die Folge der intrauterinen Anpassung ist, sondern auch für die postnatale Entwicklung des Mikrobioms wichtig ist. Mechanismen, die fetale Immunfunktionen regulieren und postpartal zur Reifung des Immunsystems führen, sind wenig verstanden.

\section{Neue Impfstoffe}

\section{DGPI-SY-NI-2}

Kombinationsimpfstoffe und Koadministration - was gibt es zu beachten?

\section{Heininger $U$.}

'Universitäts-Kinderspital beider Basel (UKBB), Basel, Schweiz

Die von der STIKO allgemein empfohlenen Impfungen richten sich gegen 14 Infektionserreger bzw. -krankheiten bei Kindern und Jugendlichen. Deren Applikation erfordert selbst unter Verwendung von Kombinationsimpfstoffen viele Injektionen und Impfterminen. Um den Aufwand für alle Beteiligten erträglich zu halten ist es üblich, verschiedene Impfstoffe gleichzeitig zu verabreichen. Das früher geltende „Dogma“, dass beliebig viele Injektions- oder orale Impfstoffe zeitgleich verabreicht werden dürfen, ohne dass es zu einer gegenseitigen Beeinträchtigung von Verträglichkeit oder Effizienz käme, gilt nur noch eingeschränkt. Vielmehr verlangen die Zulassungsbehörden heute für neue Impfstoffe Daten aus klinischen Studien zur Koadministration mit anderen Impfstoffen. Anderenfalls werden neue Impfstoffe bezüglich Koadministration mit anderen Impfstoffen nur eingeschränkt zugelassen. Die entsprechenden Fachinformationen weisen dann auf das „Fehlen von klinischen Daten“ hin. Dies kann die Koadministration von Impfungen in der Praxis erschweren, indem bei fehlenden Daten zwar formell keine Kontraindikation vorliegt, aber bei Erkrankung des Geimpften trotz Impfung die Verantwortung auf den impfenden Arzt übergehen könnte. So wurde z. B. gezeigt, dass Kombinationsimpfstoffe mit azellulären Pertussisantigenen die Immunantwort auf gleichzeitig verabreichte Hib-Konjugatimpfstoffe inhibieren können. Dies ist offenbar klinisch nicht relevant, weil dennoch schützende anti-Hib-Polysaccharid Antikörperwerte erreicht werden und auch die epidemiologischen Beobachtungen zu invasiven Hib-Infektionen unter breiter Anwendung dieser Kombinationsimpfstoffe keinen Anlass zur
Beunruhigung geben. Die konsequente Beachtung der zugelassenen Koadministrationen ist ratsam im Aufklärungsgespräch anzusprechen.

\section{DGPI-SY-NI-3 \\ Probleme bei der Einführung der Impfung gegen Meningokokken Serogruppe B}

Knuf $M$.

${ }^{1} H S K$, Dr. Horst Schmidt Kliniken GmbH, Klinikum der Landeshauptstadt Wiesbaden, Wiesbaden

Meningokokken der Serogruppe B (Men B) sind in Europa die häufigsten Erreger der bakteriellen Meningitis und des septischen Multiorganversagens. Seit Januar 2013 hat die EMA einen rekombinanten 4-Komponenten-Meningokokken B-Impfstoff (4CMenB) für Personen ab einem Alter von 2 Monaten zugelassen. Der Impfstoff könnte in Deutschland mehr als $80 \%$ der krankheitsverursachenden Meningokokken-B-Stämme erfassen. Immunogenität und Sicherheit des 4CMenB-Impfstoffes sind für unterschiedliche Impfschemata in verschiedenen Altersgruppen ab 2 Monaten untersucht worden. Aufgrund der Epidemiologie ist ein möglichst frühzeitiger Einsatz des Impfstoffes, d. h. im Säuglingsalter, sinnvoll. Andererseits weißt 4 CMenB bei der Koadministration mit „Routine-Impfstoffen“ eine deutlich höhere Reaktogenität und höhere Fieberraten auf. Dieses könnte ein Hindernis in der Anwendung darstellen. Die Koadministration bedeutet drei Injektionen in einer Sitzung. Ein solches Vorgehen stellt in Deutschland ein „Novum“ dar und dürfte auf Vorbehalte stoßen. Ferner sind seltene unerwünschte Wirkungen sowie die Reaktogenität ,im Felde“ nicht gut untersucht. Auch hieraus könnten Bedenken erwachsen. Weitere offene Fragen sind die Anwendung bei Jugendlichen (2. Inzidenzgipfel), ein etwaiges Potential für Herdenschutz, die unbekannte Dauer des Impfschutzes sowie ein etwaiger Effekt auf die Kolonisation mit apathogenen Meningokokken.

\section{„Pro und Kontra" - antibiotische Therapie bei bakteriellen Erkrankungen}

\section{DGPI-SY-PK-1 \\ Pro Antibiotikatherapie bei Tonsillitis}

\section{Adam D.}

\section{'Kinderklinik der Universität München, Grünwald}

Die Tonsillitis wird von grampositiven betahämolysierenden Streptokokken der Gruppe A (GAS) ausgelöst (Streptococcus pyogenes) und als Tröpfcheninfektion über Speichel und Nasensekrete übertragen. Die kurze Inkubationszeit beträgt 24 bis 72 Stunden. Bei Kindern zwischen 5 und 15 Jahren ist dies die Hauptursache einer Angina mit einem Häufigkeitsgipfel im Winter und im Frühling. Lokale Ausbrüche kommen überall dort vor, wo Menschen eng miteinander zusammenleben, z. B. in der Familie oder in Kindergärten und Schulen. Unter 3 Jahren ist eine Streptokokken-Angina eher selten.

Eine seltene Komplikation ist das akute rheumatische Fieber, das zwei bis vier Wochen nach der Erkrankung auftritt. Zu den Beschwerden gehören hohes Fieber, wandernde Arthritis, Karditis, Myokarditis und Endokarditis. Es handelt sich um eine immunologische Kreuzreaktion zwischen bakteriellen und humanen Antigenen. Weitere, ebenfalls seltene Komplikationen sind eine Glomerulonephritis, Nebenhöhlenentzündung, Mastoiditis, Mittelohrentzündung, Bakteriämie, Hirnhautentzündung und Pneumonie.

Die Antibiotikatherapie zielt u. a. darauf ab, diese Komplikationen zu verhindern. Sie umfasst die Gabe von oralen Penizillinen, bzw. Cephalosporinen. Bei Betalaktam-Unverträglichkeit werden Makrolide empfohlen. Bisher gibt es keine Betalaktam-resistenten GAS. Die MakrolidResistenz liegt lokal unterschiedlich zwischen 12 und $30 \%$. 


\section{Freie Vorträge}

\section{Infektionsepidemiologie}

\section{DGPI-FV-IE-1}

Schweregrad von Influenza Primo- und Reinfektionen bei Kindern im Vorschulalter - vorläufige Ergebnisse einer prospektiven Surveillance-Studie

\section{Streng A. ${ }^{1}$, Prifert $C .{ }^{2}$, Hagemann $C .{ }^{1}$, Weissbrich B. ${ }^{2}$, Sauerbrei A. ${ }^{3}$, Liese J.G. \\ 'Universitätsklinikum Würzburg, Kinderklinik und Poliklinik, Würzburg, ${ }^{2}$ Universität Würzburg, Institut für Virologie und Immunbiologie, Würz- burg, ${ }^{3}$ Universitätsklinikum Jena, Institut für Virologie und Antivirale Therapie, Jena}

Fragestellung. Es ist unbekannt, ob eine akute respiratorische Erkrankung bei Erstinfektion mit Influenzaviren (IV; Primoinfektion) schwerer verläuft als eine erneute Erkrankung (Reinfektion) durch denselben IV-Typ (A oder B).

Methoden. Von Januar bis Mai 2013 wurde Kindern im Alter von 1 bis 5 Jahren, die aufgrund einer akuten respiratorischen Erkrankung (Fieber $\geq 38,0^{\circ} \mathrm{C}$ mit Rhinitis/Husten, Symptombeginn $\leq 48 \mathrm{~h}$ ) eine Kinderarztpraxis aufsuchten, ein Rachenabstrich und eine Blutprobe entnommen. Der Abstrich wurde mit PCR auf IV A/B getestet; aus der Blutprobe wurde der IV A/B Antikörper-Status (IgG) mittels ELISAs bestimmt Primo-/Reinfektionen wurden definiert als negativer/positiver IgGStatus für den betreffenden IV-Typ. Klinische Daten zur Erkrankungsdauer wurden mit einem Patiententagebuch erhoben.

Ergebnisse. Von insgesamt 104 IV-Patienten lag IV A bei 67 (64\%) vor [35\% $\mathrm{A}\left(\mathrm{H}_{3} \mathrm{~N}_{2}\right), 29 \% \mathrm{~A}\left(\mathrm{H}_{1} \mathrm{~N}_{1}\right) \mathrm{pdmo}$ ], IV B bei 36 (35\%); das mediane Alter der IV A/B-Patienten lag bei 3,4/3,9 Jahren. 35,5\%/33,7\% waren Primoinfektionen IV A/B (medianes Alter 3,4/3,9 Jahre) und 28,8\%/1,0\% Reinfektionen IV A/B (3,5/4,2 Jahre). IV A Primoinfektionen $(\mathrm{n}=37)$ dauerten im Median 4 Tage (IQR 3-6), IV A Reinfektionen ( $n=30$ ) 4,5 Tage $(3-6,25 ; \mathrm{p}=0,367)$. Primoinfektionen mit IV A $\left(\mathrm{H}_{3} \mathrm{~N}_{2}\right)(\mathrm{n}=22)$ waren kürzer als mit IV A(H1N1)pdmog $(\mathrm{n}=15)$; im Median 4 vs. 6 Tage; $\mathrm{p}=0,027$.

Diskussion. Vorläufige Daten (2013) zeigten keinen Unterschied in der Dauer von IV A Primo- und Reinfektionen. Jedoch waren Primoinfektionen mit IV A $\left(\mathrm{H}_{3} \mathrm{~N}_{2}\right)$ signifikant kürzer als mit IV A( $\left.\mathrm{H}_{1} \mathrm{~N}_{1}\right)$ pdmo9; dies könnte auf einen milderen Verlauf hinweisen. Weitere subtypenspezifische serologische Vergleiche sind geplant.

\section{DGPI-FV-IE-2}

Pneumokokken-assoziierte Pleuraempyeme in Deutschland Ergebnisse der ESPED-Studie 2010-2013

Maier A. ${ }^{\prime}$, Keller S.', Hagemann C.', Segerer F. ${ }^{1}$, Schoen $C^{2}{ }^{2}$, van der Linden M. ${ }^{3}$, Streng A. ', Rose M. ${ }^{4}$, Liese J.G.'

'Universitätsklinikum Würzburg, Kinderklinik und Poliklinik, Würzburg, ${ }^{2}$ Institut für Hygiene und Mikrobiologie, Würzburg, ${ }^{3}$ Nationales Referenzzentrum für Streptokokken, Aachen, ${ }^{4}$ Universitätskinderklinik, Frankfurt am Main

Einleitung. Auch nach Einführung der allgemeinen PneumokokkenImpfung wurde eine Zunahme von parapneumonischen Pleuraergüssen und Empyemen (PPE/PE) im Kindes- und Jugendalter beobachtet. Fragestellung. Wie ist die Häufigkeit, der klinische Verlauf und die Serotypenverteilung von Pneumokokken-assoziierten Pleuraempyemen (P-PPE/PE)?

Methode. Deutschlandweite prospektive Surveillance-Studie mittels der „Erhebungseinheit für seltene pädiatrische Erkrankungen (ESPED)“. Eingeschlossen werden Kinder $<18$ Jahren mit PPE/PE, die $\geq 1$ Woche persistieren oder mittels Drainage behandelt werden. Erregernachweise erfolgten mittels Kultur und/oder PCR aus Pleurapunktaten und/oder Blut.

Ergebnisse. Insgesamt wurden zwischen 10/2010 und 06/2013 645 PPE/ PE Fälle erfasst. Bei 206 (35\%) von 588 Kindern wurde mindestens ein Erreger nachgewiesen. Bei 112 (54\%) wurde S. pneumoniae nachgewiesen; diese Kinder waren im Median 4 Jahre alt (IQR: 3-7) und die Krankenhausdauer betrug 18 Tage (Median; IQR: 14-26). Intensivpflichtig waren $71 \%$ der P-PPE/PE Kinder und 25\% hatten chronische Vorerkrankungen. Komplikationen wurden bei $67 \%$, mögliche bleibende Krankheitsfolgen bei $27 \%$ berichtet. $55 \%$ waren mindestens einmal gegen Pneumokokken geimpft. Bislang konnten 36 Serotypen (ST) identifiziert werden: Am häufigsten war ST 1 (17/36), gefolgt von ST $3(8 / 36)$, $\mathrm{ST} 7 \mathrm{~F}(5 / 36)$ und ST 19A $(4 / 36)$. Von den 35 Kindern mit identifiziertem ST waren 23 (66\%) mindestens einmal gegen Pneumokokken geimpft. Diskussion. Auch nach der Einführung der allgemeinen Pneumokokken-Impfung ist S. pneumoniae weiterhin der häufigste Erreger von $\mathrm{PPE} / \mathrm{PE}$. Von den identifizierten ST sind nur 5\% durch die PCV7-, jedoch $67 \%$ und $100 \%$ durch die PCV10- und PCV13-Impfung erfasst.

\section{DGPI-FV-IE-3}

Häufigkeit von 19 viralen Erregern von akuten Atemwegserkrankungen bei Kindern im Vorschulalter in Bayern während der Influenza-Saison 2013

Liese J.G. ${ }^{1}$, Prifert C. ${ }^{2}$, Hagemann C. ${ }^{1}$, Weissbrich B. ${ }^{2}$, Sauerbrei A. ${ }^{3}$, Streng A. ${ }^{?}$

'Universitätsklinikum Würzburg, Kinderklinik und Poliklinik, Würzburg, ${ }^{2}$ Universität Würzburg, Institut für Virologie und Immunbiologie, Würzburg, ${ }^{3}$ Universitätsklinikum Jena, Institut für Virologie und Antivirale Therapie, Jena

Fragestellung. In Deutschland liegen nur begrenzt Daten zur Ätiologie von akuten respiratorischen Erkrankungen (ARE) vor. In einer Surveillance-Studie untersuchten wir Kinder mit ARE-Symptomen in 23 bayerischen Kinderarztpraxen auf virale Erreger.

Methoden. Von Januar bis Mai 2013 wurde Kindern im Alter von 1 bis 5 Jahren, die sich aufgrund einer ARE (Fieber $\geq 38,0^{\circ} \mathrm{C}$ mit Rhinitis/Husten, Symptombeginn $\leq 48 \mathrm{~h}$ ) vorstellten, ein Rachenabstrich entnommen und mittels Multiplex-PCR auf 19 virale Erreger getestet (FTD ${ }^{\circ}$ Respiratory pathogens 21, Luxembourg).

Ergebnisse. Von 318 ARE-Patienten waren 285 (90\%) im Abstrich positiv: Influenzavirus (IV) $50 \%$ [18\% A( $\left.\mathrm{H}_{3} \mathrm{~N}_{2}\right), 17 \% \mathrm{~A}\left(\mathrm{H}_{1} \mathrm{~N}_{1}\right)$ pdmo $9,15 \% \mathrm{IV}$ B]; RSV A/B 25\%; Adenovirus (AdV) 18\%; humanes Bocavirus (hBoV) 13\%; Rhinovirus 11\%; humanes Metapneumovirus (hMPV) 9\%; Coronavirus OC43/229E/NL63/HKU1 9\%; Parainfluenzavirus 1-4 7\%; Enterovirus (EV) $2 \% .63 \%$ waren virale Mono- und $37 \%$ virale Koinfektionen (2 Viren 32\%, 3 Viren 3\%, 4 Viren 2\%). Den höchsten Anteil von Monoinfektionen zeigten IV ( $65 \%$ von 142 Patienten), hMPV (62\% von 26 Patienten) und RSV (50\% von 7o Patienten). Der höchste Anteil von Koinfektionen lag vor bei hBoV (92\% von 36 Patienten), EV (86\% von 7 Patienten) und AdV (80\% von 51 Patienten); die Anzahl viraler Koinfektionen nahm mit dem Alter $\mathrm{ab}(\mathrm{p}<\mathrm{O}, 001)$.

Diskussion. Bei 90\% der Kinder mit vorwiegend Infektion der oberen Atemwege konnten ein oder mehrere Erreger nachgewiesen werden. IV war der häufigsten Erreger und lag zumeist als Monoinfektion vor. Virale Koinfektionen waren häufig (37\%).

Schlussfolgerung. Bei unkomplizierten ARE ließ sich in 90\% ein viraler Erreger nachweisen. Die Saison 2013 war von IV dominiert, wodurch die Bedeutung von Kindern in der Ausbreitung der Influenza bestätigt wird. 


\section{DGPI-FV-IE-4}

Antibiotikaverbrauch an 23 deutschen Kinderkliniken: Ergebnisse einer Punktprävalenzstudie

Schuster K. ${ }^{1}$, Madarova M. ${ }^{1}$, Rippberger B. ${ }^{1}$, Henneke P. ${ }^{1,2}$, Hufnagel M. ${ }^{1}$, für das Deutsche ARPEC Projekt Netzwerk

'Zentrum für Kinder- und Jugendmedizin, Universitätsklinikum Freiburg, Sektion Pädiatrische Infektiologie und Rheumatologie, Freiburg, ${ }^{2}$ Centrum für Chronische Immundefizienz, Universitätsklinikum Freiburg, Freiburg

Hintergrund. Im Rahmen des „Antibiotic Resistance and Prescribing in European Children (ARPEC)" Projektes nahmen 23 deutsche Kinderkliniken im November 2012 an einer Punktprävalenzstudie (PPS) zum Antibiotikaverbrauch teil.

Methoden. Im November 2012 wurde eine deutschlandweite eintägige PPS bei stationären pädiatrischen Patienten durchgeführt. Dabei kam der international standardisierte und validierte ARPEC-Fragebogen zum Einsatz. Die Datenerhebung umfasste u. a. Grunderkrankungen, systemische antimikrobielle Substanzen und Indikationen. Die Krankenhäuser wurden in Universitäts- und Nicht-Universitätskliniken (UniH vs. non-UniH) und nach Region (Südwest, Südost, Nordost bzw. Nordwest) eingeteilt.

Ergebnisse. 320 pädiatrische und 101 neonatale Patienten erhielten mindestens ein antimikrobielles Medikament. Die antimikrobielle Prävalenzrate (APR) betrug 33,1\% (9,5-49,5\% CI) für pädiatrische und $21,8 \%$ $(10,5-50,0 \%$ CI) für neonatale Patienten. Bei Neonaten war eine höhere APR in den UniH (27,0\% vs. $16,7 \%$ in non-UniH) auffällig. Bei den pädiatrischen Patienten zeigte sich kein Unterschied. Im Nordwesten war die APR in NICUs und auf allgemeinen-pädiatrischen Stationen signifikant höher als in den anderen 3 Landesteilen, jedoch niedriger bei hämatoonkologischen Patienten. Die häufigste Indikation waren untere Atemwegsinfektionen (LRTI) bei pädiatrischen und Katheter-bedingten Bakteriämien bei neonatalen Patienten. Bei LRTI wurden in $24,3 \%$ Reserveantibiotika und in 40,5\% Kombinationstherapien angewendet. Schlussfolgerung. Der Einsatz von antimikrobiellen Medikamenten wird regional wie auch durch die Art des Krankenhauses beeinflusst. Es zeigt sich ein dringender Verbesserungsbedarf bei der Anwendung von Reserveantibiotika und Kombinationstherapien.

\section{DGPI-FV-IE-5}

\section{Häufigkeit eines Nachweises multiresistenter gramnegativer Erreger (MRGN) in einer Abteilung für Neonatologie}

Christoph J.', Guthmann F."'Auf der Bult, Kinder- und Jugendkrankenhaus, Neonatologie, Hannover

Fragestellung. Wir prüften die Häufigkeit von MRGN-Nachweisen in unserer Neonatologie im Zeitraum April bis Dezember 2013. Das im Epidemiologischen Bulletin Nr. 2 vom 16.01.2012 und Nr. 42 vom 21.10.2013 empfohlene mikrobiologische Screening hatten wir im Frühjahr 2013 um ein generelles Aufnahmescreening in unserer Neonatologie erweitert.

Material und Methode. Auswertung aller Nachweise multiresistenter Erreger (MRE), klinisch indiziert oder beim MRE-Aufnahme- oder Folgescreening. Grampositive Erreger werden im Weiteren nicht betrachtet (14 MRSA-Nachweise, keine VRE).

Ergebnisse. 30 MRGN-Nachweise bei 3,8\% (29/757) Aufnahmen bzw. $6,3 \%$ (480/7637) aller Patiententage betreffend, davon 7 bei 6 Frühgeborenen mit einem Geburtsgewicht unter $1500 \mathrm{~g}$ (VLBW). Somit erfolgten 23\% (7/30) der MRGN-Nachweise bei den 63 VLBWs diesen Zeitraumes (Anteil 63/757=8,3\% der Aufnahmen). Bereinigt um Mehrfachkolonisierungen ergab sich ein zeitlicher Anteil von $7,7 \%$ Besiedelungstagen (285/3694) in unserer VLBW-Population. Bei 13 Aufnahmeabstrichen war ein MRGN-E. coli nachweisbar, in 2 Enterobacter cloacae. Multiresistente Acinetobacter baumannii wurden je einmal 4 bzw. 5 Tage nach Aufnahme nachgewiesen, ferner zweimal MRGN-E. coli 5 Tage nach
Aufnahme. Die übrigen 11 MRGN-Nachweise erfolgten in späteren Surveillance-Abstrichen.

Diskussion. 63\% aller MRGN-Nachweise betrafen E. coli, verantwortlich für $38 \%$ der Tage mit Kolonisation; $17 \%$ der MRGN waren Acinetobacter baumannii, betrafen aber $38 \%$ der Patiententage (3 der 5 Nachweise bei VLBW-FG). Dies kann auf Erreger- und Patientengruppen-spezifische Besiedelungsmuster in der Neonatologie hinweisen. Bei knapp 10\% unserer VLBW-Population (Aufnahmen wie Behandlungstage) waren indizierte Hygiene- bzw. Isolationsmaßnahmen erforderlich.

\section{DGPI-FV-IE-6 \\ Infektionsepidemiologie bei 82 Kindern mit septischem Schock im Ruhrgebiet und Köln von 2009 bis 2011}

Dohna-Schwake C. ${ }^{1}$, REDMOPED

${ }^{1}$ Klinik für Kinderheilkunde I, Essen

Infektionsepidemiologische Daten bei Kindern mit septischem Schock existieren für Deutschland nicht. Diese Tatsache nahmen wir zum Anlass, eine retrospektive multizentrische Erhebung im Ruhrgebiet und in Köln zu diesem Thema durchzuführen.

Insgesamt konnten 83 Fälle bei 82 Kindern mit septischem Schock im Zeitraum von 2009 bis 2011 identifiziert werden. Die Mortalität betrug 25\%. Das Alter betrug im Median 42 Monate (Range 2-208 Monate). 47 Patienten waren weiblich, 50 Patienten hatten eine chronische Grunderkrankung und 65 Infektionen wurden ambulant erworben. Bei 17 Patienten bestand eine Leukopenie von $<2 /$ nl. Bei 32 Patienten gelang kein Keimnachweis. Folgende Keime wurden identifiziert: Meningokokken (12), gramnegative Stäbchen (5-mal Klebsiellen, 4-mal E. coli, davon 1 ESBL, 2-mal Pseudomonas, 2-mal Stenotrophomonas, 1-mal Enterobacter), Pneumokokken (4), Staphylococcus aureus (3), Staphylococcus aureus mit Toxic shock Toxin (4), koagulase-negative Staphylokokken (4), Streptococcus viridans (4), Enterokokken (3). Kein VRE und kein MRSA wurden nachgewiesen. An weiteren Keimen konnten 1-mal Campylobacter, 1-mal H1N1-Influenza und 1-mal RSV plus Haemophilus inflluenzae identifiziert werden.

Schlussfolgerung. Die meisten Fälle von septischem Schock im Kindesalter sind auch bei chronisch kranken Patienten nicht im Krankenhaus entstanden. Die Mortalität mit 25\% ist hoch. In dem untersuchten Zeitraum von 2009 bis 2011 spielten resistente Erreger eine untergeordnete Rolle.

Im Rahmen von REDMOPED (REDucing MOrtality in PEDiatric septic shock)

\section{DGPI-FV-IE-7}

Nachweis von Nicht-Polio-Enteroviren (NPEV) bei Patienten mit akuten schlaffen Paresen (AFP) im Rahmen der Enterovirussurveillance in Deutschland

Neubauer K. ${ }^{1}$, Böttcher S. ${ }^{2}$, Beyrer K. ${ }^{3}$, Diedrich S. ${ }^{2}$

${ }^{1}$ Robert Koch-Institut, Geschäftsstelle der Nationalen Kommission für die Polioeradikation in Deutschland, Berlin, ${ }^{2}$ Robert Koch-Institut, Nationales Referenzzentrum für Poliomyelitis und Enteroviren, Berlin, ${ }^{3}$ Niedersächsisches Landesgesundheitsamt, Hannover

Hintergrund. Differenzialdiagnostisch kommen für akute schlaffe Paresen (AFP) der Extremitäten verschiedene Ursachen in Betracht. Als Kardinalsymptom einer Poliomyelitis ist eine Enterovirus(EV) -Diagnostik notwendig. Zur Überwachung der Poliofreiheit wurden in Deutschland seit 1998 die AFP-Surveillance und seit 2006 die EV-Surveillance (EVSurv) durchgeführt. Dabei wird bundesweit allen Kliniken zur Abklärung von viralen Meningitiden und AFP die kostenlose EV-Diagnostik in einem Labornetzwerk (LaNED) angeboten.

Methoden. Stuhl- und/oder Liquorproben von Patienten mit AFP wurden mittels PCR, Anzucht und Typisierung untersucht. 
Ergebnisse. Seit 2006 wurden 474 Patienten mit AFP in der EVSurv untersucht. Zur Diagnostik wurden Stuhl- (63\%) oder Liquorproben (30\%) oder beides (7\%) aus dem gesamten Bundesgebiet eingesandt. Der Großteil der Patienten (72\%) waren Kinder unter 15 Jahren. In der EV-PCR waren 41 (9,8\%) der Proben positiv (93\%<15 Jahre). Dabei war die EV-Nachweisrate im Stuhl ( $78 \%$ positiv) der im Liquor ( $7 \%$ ) deutlich überlegen. Das Erkrankungsdatum EV-positiver AFP-Patienten lag überwiegend (90\%) zwischen Juli und November. Bei 26 der 41 EVpositiven Proben (63\%) konnte der Serotyp bestimmt werden: es wurden Coxsackievirus A4, A6, A8-A10, A16, B2-B4 sowie Echovirus 6, 7, 11, 18, 25 und 30 identifiziert. Polioviren wurden nicht detektiert. Erstmals wurde in Deutschland Enterovirus 71 bei zwei Patienten mit AFP nachgewiesen. Dieser Serotyp verursacht in Südostasien große HFMK-Epidemien und wurde bereits mit AFP und Todesfällen assoziiert.

Schlussfolgerung. Neben Polioviren können auch NPEV ursächlich für AFP sein. Die EVSurv ist ein geeignetes Instrument zur Überwachung der Poliofreiheit in Deutschland. Alle Patienten mit AFP sollten im Hinblick auf die globale Polioeradikation virologisch abgeklärt werden.

\section{DGPI-FV-IE-8}

Substitutionstherapie mit Immunglobulinen bei Kindern mit primären Immundefekten: SIGNS-Register

Baumann U.', Faßhauer M. ${ }^{2}$, Gold R. ${ }^{3}$, Hensel M. ${ }^{4}$, Huscher D. ${ }^{5}$, Pittrow D. ${ }^{6}$, Reiser M. ${ }^{7}$, Stangel M. ${ }^{8}$, Kirch W. ${ }^{6}$, Borte M. ${ }^{2}$, SIGNS Studiengruppe

${ }^{1}$ Medizinische Hochschule Hannover, Klinik für Pädiatrische Pneumologie, Allergologie und Neonatologie, Hannover, ${ }^{2}$ Klinikum St. Georg gGmbH, Akademisches Lehrkrankenhaus der Universität Leipzig, Fachbereich Pädiatrische Rheumatologie, Immunologie und Infektiologie, Leipzig, ${ }^{3} \mathrm{St}$. Josef-Hospital, Abt. für Neurologie, Bochum, ${ }^{4}$ Mannheimer Onkologie Praxis, Mannheim, ${ }^{5}$ Deutsches Rheuma- Forschungszentrum, Epidemiologie, Berlin, ${ }^{6}$ Technische Universität Dresden, Institut für Klinische Pharmakologie, Dresden, ${ }^{7}$ Praxis Internistische Onkologie, PIOH, Köln, ${ }^{8}$ Medizinische Hochschule Hannover, Abteilung für Neurologie, Hannover

Hintergrund. Das prospektive SIGNS-Register (NCTo1287689) dokumentiert unter anderem Kinder mit primären Immundefekten (PID), die Immunglobuline (IG) als Substitutionstherapie erhalten. Zum 7. Mai 2014 wurden 65 Kinder dokumentiert (mittleres Alter 10,2 $\pm 4,3$ Jahre; $66 \%$ Jungen). Bei 32 bestand ein CVID, bei 11 XLA, und bei 9 ein isolierter IG Subklassenmangel. Die Krankheitsdauer betrug 7,3 $\pm 4,3$ Jahre, die Dauer seit der PID-Diagnose 4,1 $\pm 3,5$ Jahre.

Methoden. Bei Einschluss erhielten 47 (72\%) Kinder subkutane (SC) und 18 (28\%) intravenöse (IV) IG-Präparate. Die mittlere 4-Wochen-Dosis betrug $380 \mathrm{mg} / \mathrm{kg}$ bei IV IG und $602 \mathrm{mg} / \mathrm{kg}$ bei SC IG ( $\mathrm{p}=0,013)$; im Verlauf betrug die durchschnittliche Dosis bei IV-Gabe $390 \mathrm{mg} / \mathrm{kg} \mathrm{KG}$ alle 4,4 Wochen und bei SC-Gabe $148 \mathrm{mg} / \mathrm{kg} \mathrm{KG}$ alle 1,2 Wochen. Damit erhielten 62 Patienten $(95,4 \%)$ durchschnittlich $\geq 200 \mathrm{mg} / \mathrm{kg} \mathrm{KG}$ bezogen auf 4 Wochen. Der mittlere IgG-Plasma-Talspiegel lag bei Einschluss bei 7,2 g/l (IV IG) bzw. 8,3 g/l (SC IG; p=0,059).

Ergebnisse. Von den 62 Kindern, die mindestens 3 Monate vor Einschluss mit IG substituiert worden waren, hatten in den 12 Monaten vor Einschluss 48 (77,4\%) unkomplizierte Allgemeininfektionen, $3(4,8 \%)$ eine Pneumonie und 1 Kind eine schwerwiegende Harnwegsinfektion. Von den 54 Kindern mit 1-Jahres-Follow-up hatten nur noch $32(59,3 \%)$ eine Allgemeininfektion und ein Kind eine Pneumonie (1,9\%).

Schlussfolgerung. Zusammenfassend besteht bei Kindern eine Präferenz zur SC IG-Behandlung. Durchschnittliche SC Dosierungen sind in der klinischen Praxis höher als IV verabreichte, wobei die Dosierungspraxis den Empfehlungen entspricht (400-60o mg/kg alle 3-4 Wochen bei IV IG-Behandlung). Der Mehrzahl der Kinder mit PID ist von Allgemeininfektionen betroffen, während schwerwiegende bakterielle Infektionen unter IG-Substitution deutlich seltener auftreten.

\section{DGPI-FV-IE-9}

Symptomatische CMV-Infektionen bei Säuglingen: erste Ergebnisse der ESPED-Studie 2012-2013

\section{Schuster K.', Speckmann C. ${ }^{1,2}$, Henneke P., ${ }^{1,2}$}

'Zentrum für Kinder- und Jugendmedizin, Universitätsklinikum Freiburg, Sektion Pädiatrische Infektiologie und Rheumatologie, Freiburg, ${ }^{2}$ Centrum für Chronische Immundefizienz, Universitätsklinikum Freiburg, Freiburg

Hintergrund. Trotz verbesserter diagnostischer und therapeutischer Möglichkeiten existieren bislang nur wenige Daten zu konnatal und postnatal erworbenen symptomatischen CMV-Infektionen.

Methoden. Von Januar 2012 bis Dezember 2013 wurden alle Säuglinge mit symptomatischen CMV-Infektionen von deutschen Kinderkliniken an die zentrale „Erhebungseinheit für seltene pädiatrische Erkrankungen in Deutschland“ (ESPED) gemeldet. Jeder gemeldete Fall wurde per standardisiertem Fragenbogen nach Diagnostik, Symptomatik, Behandlung und weiterem Verlauf ausgewertet.

Ergebnisse. Insgesamt wurden bislang 105 Patienten gemeldet. 34\% waren Frühgeborene mit einem Median von 29,5 SSW. Klinisch fielen je ein Drittel der Patienten durch Dystrophie, Hörstörung, Thrombozytopenie, Hepatitis oder neurologische Symptome auf. Eine konnatale Infektion konnte in $27 \%$ der Fälle nachgewiesen werden, eine postnatale in $37 \%$. Bei $86 \%$ konnte CMV im Urin nachgewiesen werden. Ganciclovir war das meist genutzte antivirale Therapeutikum. In $20 \%$ aller behandelten Fälle traten Nebenwirkungen auf, v. a. Neutropenie und Transaminasenerhöhung. Die Mehrzahl der Patienten wurde für 6 Wochen behandelt. Nach Behandlungsende war CMV bei $60 \%$ weiterhin im Urin nachweisbar; nur $34 \%$ der Patienten hatten sich klinisch verbessert. 10 Kinder (10\%) zeigten eine angeborene oder erworbene Immundefizienz.

Schlussfolgerung. Die Behandlung von symptomatischen CMV-Infektionen im ersten Lebensjahr bleibt eine Herausforderung, nicht zuletzt aufgrund des sehr unterschiedlichen klinischen Verlaufs und der häufigen Therapienebenwirkungen. Kontrollierte klinische Studien und Leitlinien zu Diagnostik und Therapie werden dringend benötigt. Eine behandlungsbedürftige CMV-Infektion ist regelmäßig Indikator für einen zu Grunde liegenden Immundefekt.

\section{Freie Themen}

\section{DGPI-FV-VA-1}

Hypoxie hemmt die Funktion myeloider Suppressorzellen in der Plazenta

Köstlin N.', Hofstädter K.' , Spring B. ${ }^{1}$, Poets C.F.', Gille C. ${ }^{1}$

'Universitätsklinikum Tübingen, Neonatologie, Tübingen

Hintergrund. Konnatale Infektionen sind eine wichtige Ursache für perinatale Morbidität und Mortalität. Damit verbundene Inflammationsvorgänge in der Plazenta führen zu Hypoxie, Plazentainsuffizienz, fetaler Wachstumsretardierung und Frühgeburtlichkeit. Myeloide Suppressorzellen (MDSC) sind myeloide Vorläuferzellen, die im Nabelschnurblut und im Blut gesunder Schwangerer erhöht sind und Entzündungsantworten hemmen.

Hypothese. MDSC akkumulieren in der Plazenta und ihre Funktion wird durch Hypoxie beeinflusst.

Methoden. Der Anteil an MDSC in mononukleären Zellen aus Schwangerenblut (S-PBMC), Nabelschnurblut (CBMC) und Plazentazellen (PlaC) sowie die Expression der Enzyme Arginase I und iNOS und die Produktion reaktiver Sauerstoffspezies (ROS) wurden durchflusszytometrisch ermittelt. MDSC aus PlaC wurden isoliert und zu CFSE-markierten PBMC gegeben. Nach $96 \mathrm{~h}$ Stimulation mit OKT3 und IL-2 und Kultur unter normoxischen oder hypoxischen Bedingungen wurde die T-Zell-Proliferation durchflusszytometrisch gemessen. 
Ergebnisse. Der Anteil an MDSC war in PlaC 1,5- bis 2-fach höher als in CBMC und S-PBMC. MDSC aus PlaC exprimierten die Effektorenzyme Arginase I und iNOS und produzierten deutlich mehr ROS als MDSC aus S-PBMC und CBMC. Zugabe von MDSC aus PlaC zu PBMC hemmte die IL-2/OKT-3-induzierte CD4- und CD8-T-Zellproliferation in Normoxie konzentrationsabhängig um $46 \%$ bzw. $33 \%$, während die Hemmung in Hypoxie bei nur $30 \%$ und $12 \%$ lag.

Schlussfolgerung. Die Akkumulation und funktionelle Aktivierung von MDSC in der Plazenta könnte eine wichtige Rolle für die Aufrechterhaltung der fetomaternalen Toleranz spielen. Die durch Hypoxie bedingte Funktionsbeeinträchtigung von MDSC könnte zur Pathogenese bei konnatalen Infektionen beitragen.

\section{DGPI-FV-VA-2 \\ Überexpression von BCL-2 führt zu verminderter Apoptose myeloi- der Suppressorzellen nach Phagozytose von E. coli}

Leiber A.', Schwarz J.', Köstlin N.', Spring B.', Poets C.F.', Gille C. ${ }^{1}$

'Universitätsklinik für Kinder- und Jugendmedizin Tübingen, Neonatologie, Tübingen

Fragestellung. Myeloide Suppressorzellen (MDSC) sind Vorläuferzellen von Granulozyten die Immunantworten hemmen. Vorergebnisse zeigen, dass ihre Anzahl im Nabelschnurblut (NSB) erhöht ist. Die Rolle der MDSC bei der Abwehr von Bakterien sowie ihre Apoptoseeigenschaften sind unklar. Wir untersuchten, ob MDSC aus NSB Bakterien phagozytieren, eine verminderte Apoptose zeigen und antiinflammatorische Zytokine produzieren.

Methoden. In einem In-vitro-Modell granulozytärer MDSC aus NSB wurde die Phagozytose GFP- exprimierender Escherichia coli (E. coli) mit der Phagozytoserate von Granulozyten mittels Durchflusszytometrie, Konfokal- und Elektronenmikroskopie verglichen. Die Apoptoserate wurde mittels Annexin-V/7-AAD Färbung ermittelt. Die Expression pro- (Bax) und anti- (Bcl-2, Bcl-xL) apoptotischer Bcl-Proteine sowie die Zytokinproduktion wurden durchflusszytometrisch bestimmt.

Ergebnisse. MDSC zeigten die gleiche Phagozytoserate wie Granulozyten $(38,0 \pm 18,6 \%$ vs. $39,17 \pm 11,0 \%)$. Die postphagozytäre Apotptoserate von MDSC war deutlich geringer als bei reifen Granulozyten (30,3 $\pm 12,2 \%$ vs. $64,7 \pm 26,5 \%$; $<<0,05$ ). Der Anteil Bcl-2-exprimierender Zellen $(82,7 \pm 14,4 \%$ vs. $60,4 \pm 17,5 \%$; $p<0,05)$ war bei MDSC im Vergleich zu reifen Granulozyten vor Bakterienkontakt erhöht. Nach Phagozytose sank der Anteil Bcl-2-exprimierender Zellen bei Granulozyten $(35,8 \pm 14,3 \%)$, nicht jedoch bei MDSC $(74,8 \pm 19,2 \%)$. MDSC produzierten nach Phagozytose von E. coli vermehrt IL-10 und IL-8.

Schlussfolgerung. MDSC aus NSB und reife Granulozyten haben eine vergleichbare Phagozytoserate. MDSC zeigen eine verzögerte postphagozytäre Apoptose und produzieren antiinflammatorische Zytokine. Sie könnten so für die primäre Immunantwort bakterieller Infektionen der Neonatalzeit wichtig sein.

\section{DGPI-FV-VA-3}

\section{Endogene Stresssignale wie S100A8/A9 vermitteln die mikrobielle} Toleranz von Neugeborenen

Pirr S.M. ', Austermann J. ${ }^{2}$, Burgmann J.', Friesenhagen J.', Fass/ S.K. ${ }^{2}$, Petersen B. ${ }^{2}$, Barczyk-Kahlert K. ${ }^{2}$, Ortkras T. ${ }^{2}$, von Köckritz-Blickwede M. ${ }^{3}$, Roth J. ${ }^{2,4}$, Vogl T., ${ }^{2,4}$, Viemann D. ${ }^{1}$

${ }^{1}$ Klinik für Pädiatrische Pneumologie, Allergologie und Neonatologie, Medizinische Hochschule Hannover, Hannover, ${ }^{2}$ Institut für Immunologie, Universität Münster, Münster, ${ }^{3}$ Institut für Physiologische Chemie, Tierärztliche Hochschule Hannover, Hannover, ${ }^{4}$ Interdisziplinäres Zentrum für Klinische Forschung, Universität Münster, Münster

Fragestellung. Neugeborene (NG) neigen zu überschießenden Entzündungsreaktionen. Die neonatale Sepsis ist führende Ursache der perina- talen Mortalität. In den ersten Lebenswochen (LW) müssen besiedelnde kommensale Keime toleriert und pathogene Keime abgewehrt werden. Die Immunregulation dieser kritischen Phase ist essentiell aber bislang unverstanden. Wir untersuchten erstmals, ob die endogenen Alarmine S1ooA8/A9 [„Toll-like“ Rezeptor (TLR)4-Liganden] Toleranz induzieren können und welche Rolle sie bei NG im Hinblick auf peripartale Immunregulation und Sepsis spielen.

Methoden. S10oA8/A9 wurde im Serum von gesunden und septischen NG bestimmt. In vitro wurden die Effekte von S1ooA8/A9 auf die Immunreaktion adulter und neonataler Monozyten mittels Genexpressions- und Zytokinanalysen detektiert. Die S1ooA9 knock out (ko) Maus wurde im neonatalen Endotoxinämiemodell untersucht.

Ergebnisse. S10oA8/A9-Serumspiegel gesunder RG sind massiv erhöht und steigen nur moderat im Verlauf einer Sepsis an. Die Spiegel fallen in den ersten 2 LW drastisch ab. FG weisen signifikant niedrigere Serumspiegel auf. In humanen Monozyten induziert S10oA8/A9 LPS-Toleranz. Die LPS-Antwort neonataler Monozyten ist gehemmt. Sie bleibt hyporesponsiv bei Kultur in neonatalem Plasma, nicht aber bei Kultur in adultem Plasma. Der hemmende Effekt von neonatalem Plasma wird aufgehoben durch S10oA9-Antagonisten. Neonatale S1ooA9 ko Mäuse antworten hyperinflammatorisch auf LPS mit signifikant geringerer Überlebenswahrscheinlichkeit als wt Mäuse.

Schlussfolgerung. Wir zeigen erstmals, dass S10oA8/A9 in Monozyten mikrobielle Toleranz vermittelt. Endogene TLR4-Stressliganden erweisen sich als kritische Regulatoren von Toleranz und Abwehr in der Neonatalzeit und stellen völlig neue immunmodulatorische Therapieansätze dar.

\section{DGPI-FV-VA-4}

Intrazelluläres Überleben von S. aureus SCVs in humanen Makrophagen - ein neuer Persistenzmechanismus

Mysore V. ', Tuchscher L. ${ }^{2}$, Nippe N. ${ }^{1}$, Hansen U. ${ }^{3}$, Hoerr V. ${ }^{4}$, Weinhage T. ${ }^{5}$, Fraunholz M. ${ }^{6}$, Peters G. ${ }^{2}$, Roth J.', Löffler B. ${ }^{2}$, Holzinger D. ${ }^{5}$

'Uniklinik Münster, Institut für Immunologie, Münster, ${ }^{2}$ Uniklinik Münster, Institut für Medizinische Mikrobiologie, Münster, ${ }^{3} U$ niklinik Münster, Institut für Experimentelle Muskuloskelettale Medizin, Münster, ${ }^{4}$ Uniklinik Münster, Institut für Klinische Radiologie, Münster, ${ }^{5}$ Uniklinik Münster, Klinik für Pädiatrische Rheumatologie und Immunologie, Münster, ${ }^{6} U n i-$ versität Würzburg, Institut für Mikrobiologie, Würzburg

Fragestellung. Persistenzmechanismen von S. aureus während chronischer Infektionen sind nur wenig verstanden. S. aureus ist in der Lage einen bestimmten Phänotyp anzunehmen („small colony variants“, SCV), der in nichtprofessionellen Wirtszellen überleben kann. Daher wurde in dieser Studie das intrazelluläre Überleben in Makrophagen als Mechanismus der Persistenz und Disseminierung im Wirt untersucht.

Material und Methoden. Humane Makrophagen (hMDM) wurden mit verschiedenen S. aureus SCV-Stämmen infiziert und Persistenz, Zytotoxizität sowie Freisetzung in vitro mittels Kulturmethoden, Elektronen- sowie Fluoreszenzmikroskopie charakterisiert. In einem murinen Infektionsmodell wurde in vivo mittels Histologie, Kulturmethoden und Zytokinmessungen die Persistenz, Disseminierung und Immunantwort gemessen. Die Rolle des bakteriellen agr-System wurde mittels RT-PCR und $\triangle$ agr S.-aureus-Mutanten definiert.

Ergebnisse. Klinische S.-aureus-SCV-Isolate sind in der Lage, in hMDM für mehr als 12 Tage zu überleben, zeigen geringe zytotoxische Effekte und eine geringe proinflammatorische Wirkung im Vergleich zu Wildtypen. Die Freisetzung der Bakterien nach 9 bis 12 Tagen könnte eine wichtige Rolle bei der Gründung einer chronischen Infektion spielen. In vivo können SCVs durch einen agr-abhängigen Mechanismus im Wirt persistieren und sich ausbreiten.

Schlussfolgerung. SCVs nutzen die Persistenz in professionellen Phagozyten als Überlebensstrategie. Einige aber nicht alle klinischen Isolate können durch Aktivierung des agr-Systems den phagolysosomalen Ab- 
bau überleben, vermehren sich intrazellulär und werden schließlich von ihren Wirtszellen freigesetzt. Dadurch wird in vivo eine persistierende Infektion und Disseminierung zu verschiedenen Organen ermöglicht.

\section{DGPI-FV-VA-5}

Molekulare Epidemiologie von invasiven neonatalen Gruppe-BStreptokokken-Isolaten in Deutschland

Lander F.', Zürn K.', Wirth E. ${ }^{2}$, Krause G. ${ }^{3}$, Heinrich B. ${ }^{4}$, von Kries R. ${ }^{5}$, Hufnagel $M .{ }^{6}$, Berner R. ${ }^{1}$, ESPED-Studiengruppe

'Universitätsklinikum Carl Gustav Carus, Klinik und Poliklinik für Kinderund Jugendmedizin, Dresden, ${ }^{2}$ Robert Koch-Institut, Abteilung für Infektionsepidemiologie, Berlin, ${ }^{3} \mathrm{Helmholtz-Zentrum} \mathrm{für} \mathrm{Infektionsforschung,}$ Braunschweig, ${ }^{4}$ Koordinierungszentrum für Klinische Studien der HeinrichHeine-Universität, Düsseldorf, ${ }^{5}$ Ludwig-Maximilians-Universität, Institut für Sozialpädiatrie und Jugendmedizin, München, ${ }^{6}$ Universitätsklinikum Freiburg, Zentrum für Kinder- und Jugendmedizin, Freiburg

Fragestellung. Gruppe-B-Streptokokken (GBS) sind auch in den Zeiten eines universellen Schwangeren-Screenings und der Empfehlung zur intrapartalen Antibiotika-Prophylaxe weiterhin die häufigsten Erreger von invasiven Infektionen bei Neugeborenen und jungen Säuglingen und verursachen eine relevante Krankheitslast. Ziel unserer Untersuchungen ist die molekulare Epidemiologie dieses Erregers zu beschreiben und auftretende zeitliche Trends zu erkennen mit Relevanz für eine Impfstoffentwicklung gegen GBS oder ein besseres Verständnis der Pathogenese.

Material und Methode. In zwei Zeiträumen in den Jahren 2001 bis 2003 und 2008 bis 2010 konnte in Zusammenarbeit mit der Erfassungseinheit für seltene pädiatrische Erkrankungen in Deutschland und dem Robert-Koch-Institut eine umfassende Sammlung von invasiven GBS Isolaten von Neugeborenen und Säuglingen bis zum Alter von drei Monaten aufgebaut werden. Insgesamt wurden 296 Isolate in den Jahren 2001-2003 und 234 Isolate in den Jahren 2008 bis 2010 eingesandt. Diese Isolate wurden mittels eines DNS-Microarrays bezüglich Serotypen, Resistenzgenen, Pili-Gruppen, Oberflächen-Markern und weiteren $\mathrm{Pa}$ thogenitätsfaktoren untersucht.

Schlussfolgerung. In der gemeinsamen Analyse von molekularem Profil und vorliegenden klinischen Daten erlaubt diese, bei GBS bisher noch nicht in einem solchen Umfang eingesetzte Methode, relevante Aussagen zur molekularen Epidemiologie von Gruppe-B-Streptokokken.

\section{DGPI-FV-VA-6}

\section{Nekrotisierende Fasziitis - nur ein chirurgisches Problem?}

Winkler A.', Bruns R.', Barthlen W.', Wegner M.', Bahlmann H.', Beyersdorff A.', Lode H.'

'Universitätsmedizin Greifswald, Klinik für Kinder- und Jugendmedizin, Greifswald, ${ }^{2}$ Universitätsmedizin Greifswald, Klinik für Kinderchirurgie, Greifswald

Einleitung. Die nekrotisierende Fasziitis ist eine seltene, potentiell lebensbedrohliche, sich foudroyant ausbreitende Weichteilinfektion. Typ I: Polymikrobielle Infektionen mit mindestens einem anaeroben Erreger und obligat aeroben Erregern. Typ II: A-Streptokokken.

Kasuistik. 14-jährige Patientin im septischen Schock 4 Wochen nach Exzision eines Pilonidalsinus. Ambulant hochdosierte Therapie mit Metamizol bei starken Schmerzen. Bei Aufnahme: ausgeprägte Nekrosen und eitrige Wunden im Sakral- und Genitalbereich, Wundhöhle von $5 \times 5 \times 10 \mathrm{~cm}$ Größe in der Rima ani. Wundabstrich: anaerob-aerobe Mischkultur mit Pseudomonas aeruginosa, Providencia stuartii, Peptostreptococcus sp. sowie Bacteroides sp. Blutkultur: Pseudomonas aeruginosa.

Therapie und Verlauf. Sepsistherapie mit Volumensubstitution, Katecholamingabe, antibiotischer Therapie, Beatmung sowie initiale chirurgische Wundversorgung. Anfangs breite kalkulierte antimikrobielle
Therapie mit guter Gewebegängigkeit. Nach Erhalt des Resistogramms Anpassung und Optimierung der Therapie. Mehrfache großzügige Wunddébridements mit Teilresektion des Steißbeines, unter Erhalt des Rektums und des inneren Genitales mit Resektion der äußeren Labien. Komplizierend: Aggravierung durch anhaltende Agranulozytose nach Beherrschung der Sepsis, so dass es trotz adäquater antibiotischer Therapie nicht zur Wundheilung kam. Erfolgreiche Therapie dieser metamizolinduzierten Agranulozytose mit humanen rekombinanten Wachstumsfaktoren. Langsam einsetzende Wundheilung, insgesamt sehr langwieriger Verlauf über Monate.

Schlussfolgerung. Bei der Patientin fand sich eine nekrotisierende Fasziitis, dem Typ I zuzuordnen. Nur durch die chirurgische Versorgung sowie resistogrammgerechte antibiotische Therapie ist der foudroyante Verlauf beherrschbar gewesen.

\section{DGPI-FV-VA-7 \\ NTM Kids - Studie zu Lymphadenitis durch nichttuberkulöse Myko- bakterien im Kindesalter}

Kuntz M. ', Seidl M. ${ }^{2,3}$, Hufnagel M. ${ }^{1}$, Nieters A. ${ }^{3}$, Henneke P. ${ }^{1,3}$

${ }^{1}$ Universitätsklinikum Freiburg, Zentrum für Kinder- und Jugendmedizin, Freiburg, ${ }^{2}$ Universitätsklinikum Freiburg, Department für Pathologie, Freiburg, ${ }^{3}$ Universitätsklinikum Freiburg, Centrum für Chronische Immundefizienz, Freiburg

Fragestellung. Risikofaktoren, die immungesunde Kinder für eine Lymphadenitis durch nichttuberkulöse Mykobakterien (NTM) prädisponieren, sind noch unzureichend aufgeklärt. Darüber hinaus fehlen etablierte Parameter zur Auswahl des optimalen therapeutischen Vorgehens.

Methoden. NTM Kids ist eine multizentrische epidemiologische Fallkontrollstudie. Es werden Patienten mit nachgewiesener NTM-Lymphadenitis eingeschlossen, sowie nach Alter, Geschlecht und Zentrum kontrollierte gesunde Kontrollen. Per Fragebogen werden Daten zur Exposition, medizinischen Geschichte und zum soziodemographischen Status erfasst. Für die NTM-Patienten werden außerdem die Art und der Zeitpunkt der Therapie und der Verlauf der Erkrankung sowie eventuelle Residualzustände erhoben. Daneben wird der histologische Befund ggf. entfernter Lymphknoten nach einem standardisierten Schema analysiert. Zusätzlich werden epigenetische Marker zwischen Patienten und Kontrollen verglichen.

Ergebnisse. Mehr als 100 Patienten aus deutschsprachigen Ländern mit nachgewiesener zervikaler NTM-Lymphadenitis und entsprechende Kontrollen konnten bislang eingeschlossen werden, die Rekrutierung dauert an. Eine erste Zwischenauswertung deutet auf einen tendenziell höheren sozioökonomischen Status in der Patientengruppe hin. Eine erhöhte allgemeine Infektanfälligkeit, Unterschiede bei der Durchimpfungsrate oder dem Expositionsverhalten konnten nicht beobachtet werden.

Diskussion. Neue Daten zu Risikofaktoren für eine NTM-Lymphadenitis werden das Verständnis dieser Krankheit verbessern und sollen zur Vorbereitung einer Interventionsstudie dienen.

\section{DGPI-FV-VA-8}

Schwierige Therapie bei multifokalem Tuberkulose-Rezidiv (ZNS, Knochen, Weichteil) und Kurzdarmsyndrom mit vollparenteraler Ernährung beim Jugendlichen

Berlemann B. ', Pohl C.', Seiffert P.'

'HELIOS St. Johannes-Klinik, Pädiatrie, Duisburg

Fragestellung. Welches Therapieregime bei Tbc-Rezidiv und Kurzdarm?

Material und Methoden. 17-jähriger Patient mit Z. n. Volvulus vor 9 Jahren, nahezu totaler Dünndarmresektion und Z. n. kulturell offener Lungen-Tbc 2010. Damals 2-fach Therapie mit Ethambutol i.v. 
und Streptomycin i.m. Im Sommer 2013 Tbc-Rezidiv mit identischem Keimnachweis (Kulturen aus Magensaft, Bronchialsekret und Punktat aus Weichteilgewebe). Keine Resistenzen nachgewiesen. Evaluation der Ausbreitung der Tbc mittels Skelettszintigraphie, CTs und MRTs. Nachweis aktiver Herde an Dura intrazerebral, Conchae, in $\mathrm{LWK}_{3} / 4$ und paravertebral dorsal der LWK im Weichteilgewebe. Ermittlung von Pharmakokinetiken nach oraler Applikation verschiedener Tuberkulostatika in wechselnden Dosierungen unter gleichzeitiger i.v.-Applikation der Nahrung und ergänzenden Tuberkulostatika.

Ergebnisse. Entschluss zur 4-fach-Therapie mit Pyrazinamid (PZA) + Levofloxacin (LEV) oral in hoher Dosis (4 Monate) und Rifampicin (RIF) + Isoniazid (INH) i.v. über Broviak. Bei Kontrollen deutliche Regredienz der Herde und nach Absetzen von PZA und LEV nun gute Pharmakokinetiken für RIF und INH oral in hoher Dosis und folgend Umstellung der Behandlung. Nach 11 Monaten keine Herde nachweisbar. Prozedere: Fortführen der oralen Therapie für mindestens 4 Monate.

Diskussion und Schlussfolgerung. Bei komplexer Vorgeschichte musste ein alternatives Therapieregime etabliert werden, welches nur teilparenteral erfolgen musste und letztlich komplett oralisiert werden konnte. Hierunter sehr gutes Therapieergebnis und Compliance. Pharmakokinetiken sind hier ein sehr hilfreiches Instrument. Eine Verlängerung der Therapiedauer scheint im vorliegenden Fall sinnvoll. Ob so eine Restitutio ad integrum herbeigeführt werden kann, bleibt noch offen.

\section{DGPI-FV-VA-9}

\section{BCG - ein stumpfes Schwert im Kampf gegen die Tuberkulose?}

von Both U. ', Berk M.', Sridhar S. ${ }^{2}$, Newton S.M. ', Levin M.

'Imperial College, Paediatric Infection and Immunity, London, Vereinigtes Königreich, ${ }^{2}$ Imperial College, Respiratory Research Unit, London, Vereinigtes Königreich

Fragestellung. Tuberkulose verursacht jährlich ca. 1,4 Mio. Todesfälle, obwohl BCG eine der weltweit am meisten verabreichten Impfungen ist. $10-15 \%$ aller Fälle in endemischen Gebieten betreffen Kinder $<15$ Jahren, bei denen Diagnose und Therapie große Probleme darstellen. Über 90 Jahre seit ihrer Einführung besteht die Ansicht, dass BCG als Impfung versagt hat. $\mathrm{Zu}$ den zahlreichen Versuchen, neue TB-Impfansätze zu identifizieren, zählt auch, die Immunogenität von BCG zu verbessern. Diese Arbeit soll helfen, die humane Immunantwort gegen BCG und das grundlegende Problem dieser Impfung besser zu verstehen.

Material und Methoden. Ex-vivo-Stimulation von Vollblut gesunder Spender mit M. bovis BCG und RNA-Gewinnung an aufeinanderfolgenden Zeitpunkten bis $96 \mathrm{~h}$. Nicht-stimulierte Proben dienten als interne Kontrolle. Verwendung von Illumina HT12v4 microarrays gefolgt von statistischer und funktionsbiologischer Analyse des Genom-weiten humanen RNA-Expressionsmusters. Evaluation der Proteinexpression mittels FACS und ELISA

Ergebnisse. Zur statistischen Analyse der dynamischen Geneexpression wurde eine neue biostatistische Methodik entwickelt. Etwa 4000 Gene wiesen signifikante Unterschiede ihrer Expression infolge Stimulation mit BCG auf, 54\% davon waren hoch- und $46 \%$ herunterreguliert. Die Analyse der betroffenen biologischen Signalwege zeigte u. a. reduzierte Expression wichtiger Gene, die an interzellulärer Kommunikation, Antigen-Präsentation und Phagolysosom-Reifung beteiligt sind. Die Ergebnisse wurden auf Protein Ebene validiert.

Schlussfolgerung. BCG induziert eine Immunsuppression auf Transkriptom-Ebene und beeinträchtigt dadurch die Entwicklung einer ausreichenden Impfantwort. Ansätze für neue BCG-basierte Impfungen sollten vor diesem Hintergrund kritisch überdacht werden.

\section{Poster}

\section{Erregerbedingte Respirationstrakterkrankungen und Mykobakteriosen}

\section{DGPI-PO-ER-1}

Stellenwert von Procalcitonin und C-reaktivem Protein in der Diagnostik respiratorischer Adenovirus-Infektionen bei Kindern

Kunze W.', Klemm T.', Streidl J.-P.'

${ }^{1}$ Muldentalkliniken, Abteilung Kinder- und Jugendmedizin, Wurzen, ${ }^{2} \mathrm{MVZ}$ Labor Dr. Reising-Ackermann u. Kollegen, Leipzig

Hintergrund. Bei bis zu 80\% der Patienten mit respir. AdV-Infektionen ist das CRP $>40 \mathrm{mg} / \mathrm{l}$ erhöht. Es stellt sich die Frage, ob es sich um eine Besonderheit der AdV-Infektion handelt oder dies durch eine bakterielle Superinfektion bedingt ist.

Ziel. Klärung, inwiefern PCT-Bestimmungen bei deutlich erhöhten CRP-Werten eine Differenzierung bakterieller von AdV-Infektionen ermöglichen.

Patienten und Methoden. Datenauswertung von 35 Kindern mit PCRgesicherten, AdV-Infektionen. Gegenüberstellung: 1: PCT <0,5 $\mu \mathrm{g} / 1$ $(\mathrm{n}=21), 2: \geq 0,5 \mu \mathrm{g} / \mathrm{l}(\mathrm{n}=14)$. Labor: PCT, CRP, Leukozyten, IL-6, Blutkulturen, StrepA-Test.

Ergebnisse. Ergebnisse bzgl. Alter, Temperatur, Therapiedauer, CRP, Leukozyten und IL-6 bieten keine signifikanten Unterschiede. PCT in Gruppe $10,21 \pm 0,11 \mu \mathrm{g} / \mathrm{l}(\mathrm{MW} \pm \mathrm{SD})$, median 0,2 ; in Gruppe 2 $1,45 \pm 1,18 \mu \mathrm{g} / \mathrm{l}$, median $\mathrm{o}, 87$ ( $\mathrm{p}=\mathrm{o}, \mathrm{ooo})$. Hohen PCT-Werten von 3,0 und $4,52 \mu \mathrm{g} / \mathrm{l}$ stehen CRP-Daten mit 11 und $40 \mathrm{mg} / \mathrm{l}$ (ARI) bei spontaner Entfieberung ohne AB-Therapie gegenüber. Blutkulturen ohne Erregernachweis.

Diskussion. AdV-Infektionen können bakterielle Infektionen imitieren. Die Folge sind AB-Gaben in einer Häufigkeit bis 91,2\%. Eine Abgrenzung von bakteriellen Infektionen ist bei diesem Krankheitsbild mit klassischen Methoden nicht möglich. In der Kombination von PCT $<0,5 \mu \mathrm{g} / \mathrm{l}$ und CRP <40 mg/l, einer Sensitivität von $97 \%$ und eine Spezifität von $61 \%$ wird mit einer Wahrscheinlichkeit von $<1 \%$ bzw. $<3 \%$ eine schwere bakterielle Infektion ausgeschlossen. Ein PCT-Wert von $\leq 0,5$ (bzw. $\leq o, 8) \mu \mathrm{g} / \mathrm{l}$ eignet sich zur Differenzierung von Krankheitsverläufen mit erhöhtem CRP und damit zur Abgrenzung von AdV- gegen bakterielle Infektionen.

Schlussfolgerung. PCT-Werte von $\leq 0,5 \mu \mathrm{g} / \mathrm{l}$ bei PCR-gesicherter AdVInfektion und hohem CRP schließen eine bakterielle Infektion aus.

\section{DGPI-PO-ER-2}

RSV-Screening und Isolierungsstrategien in hospitalisierten Kindern unter 2 Jahre mit respiratorischem Infekt

\section{Pfeil J.1,2, Tabatabai J. ${ }^{3}$, Grulich-Henn J.', Schnitzler P. ${ }^{3}$}

'Zentrum für Kinder- und Jugendmedizin Universität Heidelberg, Allgemeine Pädiatrie, Heidelberg, ${ }^{2}$ Deutsches Zentrum für Infektiologie, Heidelberg, ${ }^{3}$ Department für Infektiologie, Universitätsklinikum Heidelberg, Virologie, Heidelberg

Hintergrund. Nosokomiale Infektionen durch Respiratory Syncytial Virus (RSV) sind ein bedeutendes Problem in der Kinderheilkunde. Durch gezielte Hygiene- und Isolierungsmaßnahmen kann das Risiko nosokomialer Infektion minimiert werden. Dies setzt allerdings eine frühzeitige Erkennung von RSV-Infektionen voraus. Häufig werden dazu RSV-Antigen-Schnelltest verwendet. Diese Tests haben jedoch nur eine geringe Sensitivität, sodass viele falsch negative Ergebnisse auftreten. Das Ziel unserer Arbeit war es zu untersuchen, ob falsch negative Schnelltestergebnisse mit klinischen Parametern, die zum Zeitpunkt der stationären Aufnahme erhoben werden, assoziiert sind. 
Methoden. Wir führten eine retrospektive Analyse in einer Kohorte von 242 hospitalisierten Kindern unter 2 Jahren mit respiratorischem Infekt durch. Wir untersuchten diese Kohorte auf eine Assoziation von klinischen Parametern mit falsch-negativem vs. Richtig-negativem Schnelltestergebnis. Im Folgenden simulierten wir verschiedene Isolierungsstrategien unter Berücksichtigung der Schnelltestergebnisse und der klinischen Parameter.

Ergebnisse. Eine längere Dauer respiratorischer Symptome bei Aufnahme und die respiratorische Aufnahmediagnose konnten als unabhängige Risikofaktoren für ein falsch negatives Schnelltestergebnis identifiziert werden. Bei einer prä-test RSV-Wahrscheinlichkeit von $65 \%$ werden je nach Isolierungsstrategie 0-24\% der RSV-positiven Patienten nicht isoliert.

Schlussfolgerung. Klinische Parameter sind zum Zeitpunkt der stationären Aufnahme mit falsch negativen RSV-Schnelltestergebnissen assoziiert. Die Einbeziehung dieser klinischen Parameter in eine Isolierungsstrategie kann die Zahl nicht isolierter, RSV-positiver Patienten reduzieren.

\section{DGPI-PO-ER-3}

High flow nasal cannulae therapy - eine Therapieoption bei viraler Bronchiolitis

Wolfram J.', Bruns R.', Beyersdorff A. ', Zimmermann K. ${ }^{2}$, Heckmann M.', Bahlmann H.'

'Zentrum für Kinder- und Jugendmedizin Universitätsklinik Greifswald, Greifswald, ${ }^{2}$ Friedrich- Loeffler- Institut für Medizinische Mikrobiologie, Greifswald

Einleitung. Bronchiolitis wird durch verschiedene Viren verursacht und geht mit einer respiratorischen Insuffizienz einher. Die Therapie basiert auf symptomatischen Maßnahmen. Als Weiterentwicklung der CPAPAtemhilfe steht die High Flow Nasal Cannulae Therapy (HFNCT) für die nichtinvasive Applikation eines angewärmten und angefeuchteten Luft- Sauerstoff-Gemisches zur Verfügung. Wir berichten dazu über erste Erfahrungen.

Fall I. 4-jährige Patientin mit prolongiertem Verlauf einer afebrilen Infektion der oberen und unteren Atemwege. Am 5. Behandlungstag akute respiratorische Verschlechterung, Tachydyspnoe ( $95 / \mathrm{min}$ ), periphere Sauerstoffsättigung $84 \%$ und Atemwegsobstruktion. Erreger: Rhino/Enteroviren. Verlauf: HFNCT 15 l/min, $\mathrm{FiO}_{2}$ max. o,8, Inhalationstherapie mit $\beta_{2}$-Sympathomimetika, Therapiedauer 6 Tage.

Fall II. 2-jährige Patientin mit Husten und Fieber seit $>48$ Stunden, ausgeprägte Atemwegsobstruktion, Tachydyspnoe $(80 / \mathrm{min})$, periphere Sauerstoffsättigung von 92\%. Erreger: Bocavirus. Verlauf: HFNCT 81 1/ min, $\mathrm{FiO}_{2}$ max. 0,5, Inhalationstherapie mit $\beta_{2}$-Sympathomimetika, Therapiedauer 3 Tage.

Fall III. 3 Monate alter Patient mit afebriler Infektion der oberen Atemwege, nach 2 Tagen akute Verschlechterung mit ausgeprägter Tachydyspnoe (105/min), periphere Sauerstoffsättigung $85 \%$. Erreger: Metapneumovirus. Verlauf: HFNCT 6 1/min, $\mathrm{FiO}_{2}$ max. 0,5, Inhalationstherapie mit $\beta_{2}$-Sympathomimetika und hypertoner Kochsalzlösung, Therapiedauer 3 Tage.

Schlussfolgerung. Bei den vorgestellten Patienten war als Folge einer Remission der respiratorischen Insuffizienz die schnelle Reduktion des inspiratorischen Flows und der Sauerstoffzufuhr möglich. Die Anwendung der HFNCT bei Säuglingen und Kleinkindern wurde gut toleriert und kann die stationäre Behandlung verkürzen.

\section{DGPI-PO-ER-4}

Veränderung der nasopharyngealen Besiedlung bei Kindern bis zum 5. Lebensjahr in Deutschland seit Einführung der Pneumokokken-Konjugatimpfung

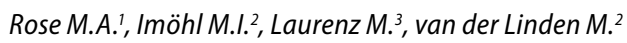

${ }^{1}$ Sana Klinikum Offenbach, Kinder- und Jugendmedizin, Offenbach, ${ }^{2} \mathrm{Na}$ tionales Referenzzentrum für Streptokokken, Aachen, ${ }^{3}$ Pfizer Deutschland $\mathrm{GmbH}$, Impfstoffe, Berlin

Fragestellung. Die Routine-Impfung mit Pneumokokken-Konjugatimpfstoffen (PCV) wurde im Juli 2006 in Deutschland für alle Kinder bis zum vollendeten zweiten Lebensjahr empfohlen und seitdem flächendeckend durchgeführt mit nachfolgend massiver Reduktion invasiver Pneumokokkenerkrankungen. Die Impfung begann mit PCV-7, welcher später durch PCV-10 und PCV-13 ersetzt wurde. Diese Untersuchung erfasst im Rahmen der WHO-empfohlenen Surveillance von Improgrammen den Einfluss auf die nasopharyngeale Besiedlung gesunder Impflinge.

Methoden. Untersuchung nasopharyngealer Abstriche vor der ersten Impfung, nach der dritten (Alter 9-12 Monate), nach der vierten (Alter 17-19 Monate) und mit fünf Jahren auf Streptococcus pneumoniae, Moraxella catarrhalis, Haemophilus influenzae und Streptococcus pyogenes. Die Serotypisierung von S. pneumoniae erfolgte durch die Neufeldsche Quellungsreaktion.

Ergebnisse. Wir berichten Zwischenergebnisse bis zum vierten Abstrich. Es konnten 242 Kindern mit einem ersten Abstrich in die Studie eingeschlossen werden. Ein vierter Abstrich lag bisher bei 129 Kindern vor. S. pneumoniae war in Abstrich 1 in 15,8\% der Fälle und in Abstrich 4 in 34,9\% nachweisbar. Für M. catarrhalis wurde bei Abstrich 3 (33,3\%), für $\mathrm{H}$. influenzae bei Abstrich $4(35,7 \%)$ und für S. pyogenes bei Abstrich $4(4,7 \%)$ die häufigste Besiedlung gefunden. PCV-7-Serotypen fanden sich in Abstrich $1 \mathrm{zu}$ 15,8\% und in Abstrich $4 \mathrm{zu} 0 \%$. PCV-13Serotypen fanden sich in Abstrich 1 zu 36,8\% und in Abstrich $4 \mathrm{zu}$ 8,9\%. Schlussfolgerung. Im Alter von fünf Jahren waren PCV-7-Serotypen bisher bei keinem Kind nachweisbar, PCV-13-Serotypen waren mit ca. 9\% niedrig im Sinne eines andauernden direkten Schutzes sowie sich etablierenden, aber noch nicht vollständigen Herdenschutz bei diesen Serotypen hin.

\section{DGPI-PO-ER-5}

Meningo-Enzephalitis durch Pneumokokken (Serotyp 23A) mit Multiorganversagen und Rhabdomyolyse

\section{Pechmann A.', Krause J.C. ', Fuchs H. ${ }^{1}$, Henneke P., ${ }^{1,2}$, Hufnagel M. ${ }^{1}$}

'Zentrum für Kinder- und Jugendmedizin, Universitätsklinikum Freiburg, Freiburg, ${ }^{2}$ Centrum für Chronische Immundefizienz, Universitätsklinikum Freiburg, Freiburg

Einleitung. Häufige Ursachen für Rhabdomyolyse im Kindesalter sind virale Infektionen (v. a. Influenza A/B, CMV, EBV), sowie Traumata. Bakterielle Infektionen sind seltene Auslöser. Bei Pneumokokken-Infektionen im Kindesalter ist diese Komplikation bislang nicht beschrieben.

Fallbericht. Ein 15 Monate alter Junge präsentierte sich mit Fieber, Husten, Schnupfen und Erbrechen. Ein tonisch-klonischer Krampfanfall führte zur stationären Aufnahme. Dort erfolgte nach einem 2. Krampfereignis mit persistierender Vigilanzminderung eine Lumbalpunktion. Im Liquor zeigte sich eine Pleozytose, kulturell konnten Pneumokokken (Serotyp 23A) nachgewiesen werden. Eine Therapie mit Ceftriaxon und Dexamethason wurde initiiert. Im Verlauf Auftreten von Oligurie, Transaminasen-Erhöhung, DIC, katecholaminpflichtiger Kreislaufinsuffizienz, transfusionspflichtiger Anämie und Thrombozytopenie, sowie einer ausgeprägten Rhabdomyolyse (CK 27.406 U/l). Eine Multiplex-PCR auf respiratorische Viren konnte Bocaviren nachweisen. Bei fehlenden Fragmentozyten und nur geringem Kreatininanstieg waren die Kriterien für ein HUS nicht erfüllt. Unter einer Therapie mit Furo- 
semid und Flüssigkeitsrestriktion setzte rasch eine suffiziente Diurese ein. Im Verlauf traten weitere Komplikationen auf in Form einer Hyperinflammations-Reaktion, Taubheit links, hochgradiger Schwerhörigkeit rechts, Hydrocephalus malresorptivus, hyperintenser Läsionen beider Thalami, sowie eines statomotorischen Rückschrittes.

Schlussfolgerung. Eine Rhabdomyolyse ist eine bisher nicht beschriebene Komplikation einer schweren Pneumokokken-Infektionen im Kindesalter. Allerdings ist eine Abgrenzung der Pneumokokken in der pathogenetischen Bedeutung zur vorangegangenen Bocavirus-Infektion und zum komplizierten Krampfgeschehen nicht zu treffen.

\section{DGPI-PO-ER-6}

Akute respiratorische Infektionen bei Kleinkindern in Kindertagesstätten und deren Erfassung mittels Symptomtagebuch und Nasenabstrich durch die Eltern

Zoch B. ', Karch A. ', Akmatov M. ', Raupach-Rosin H. ', Rübsamen N.', Dreesman J. ${ }^{2}$, Monazahian M. ${ }^{2}$, Mikolajczyk R. ${ }^{1}$

${ }^{1}$ Helmholtz-Zentrum für Infektionsforschung, Epidemiologische und Statistische Methoden, Braunschweig, ${ }^{2}$ Niedersächsisches Landesgesundheitsamt, Mikrobiologie, Infektionsschutz, Krankenhaushygiene, Infektionsepidemiologie und Gesundheitsberichterstattung, Hannover

Fragestellung. Um den Einfluss von Häufigkeit und Abfolge von Infektionen und Impfungen auf die Entwicklung des Immunsystems im Kleinkindalter untersuchen zu können, ist eine genaue Erhebung der Krankheitssymptome sowie eine Erfassung der verantwortlichen Erreger notwendig. Ziel dieser Machbarkeitsstudie war es deshalb in Vorbereitung auf eine entstehende infektiologische Geburtskohorte, die Einsatzmöglichkeit eines Symptomtagebuchs und die Durchführbarkeit von Probenentnahmen durch die Eltern zur Erfassung akuter respiratorischer Erkrankungen im Kleinkindalter zu untersuchen.

Methoden. Die Rekrutierung der Teilnehmer erfolgte in 43 Kindertagesstätten in Braunschweig. Über den Studienzeitraum von drei Monaten führten die Eltern ein Symptomtagebuch und entnahmen während jeweils einer akuten Infektion pro Kind Nasenabstriche.

Ergebnisse. Es konnten 75 Eltern aus insgesamt 24 Kitas für die Studienteilnahme ihres Kindes gewonnen werden. Das durchschnittliche Alter der teilnehmenden Kinder betrug 24 Monate (Range: 6-38 Monate). Die letzten Teilnehmer haben im März 2014 mit der Studie begonnen und werden die Studie im Juni 2014 beenden. Es wurden bisher $34 \mathrm{Na}$ senabstriche während akuter Symptome bei den Kindern untersucht Ergebnisse hinsichtlich der Vollständigkeit der Symptomtagebücher, der Anzahl und Schwere von Infektionen und hinsichtlich des Vorkommens viraler respiratorischer Erreger in den akuten Nasenabstrichen werden präsentiert.

Schlussfolgerung. Die Erfassung von Infektionen im Kindesalter verlangt eine symptomgetriggerte Probenentnahme. Inwiefern diese durch die Eltern durchgeführt werden kann, wird in unserer Studie untersucht werden.

\section{DGPI-PO-ER-7}

Die Bayerische Landesarbeitsgemeinschaft Impfen (LAGI) - eine erfolgreiche Partnerschaft von industrieunabhängigen Akteuren im Impfwesen

\section{Ludwig M.-S.', Nennstiel-Ratzel U. ${ }^{2}$, Hierl W. ${ }^{3}$, Wildner M. ${ }^{2}$, Liebl B. ${ }^{2}$}

'Bayerisches Landesamt für Gesundheit und Verbraucherschutz, Erlangen, ${ }^{2}$ Bayerisches Landesamt für Gesundheit und Verbraucherschutz, Oberschleißheim, ${ }^{3}$ Bayerisches Staatsministerium für Gesundheit und Pflege, München

Hintergrund. Die Akzeptanz von Impfungen und damit der Impfschutz in der Bevölkerung sollte in Bayern erhöht werden. Vor diesem Hintergrund wurde im November 2006 im Rahmen des Bayerischen Impf- konzeptes die industrieunabhängige Bayerische Landesarbeitsgemeinschaft Impfen (LAGI) gegründet.

Methoden. Mitglieder der LAGI sind Vertreter von Ärzteverbänden (u. a. Kinderärzte), Apothekern, Hebammen, Körperschaften, dem ÖGD, Krankenkassen und Wissenschaft einschließlich der bayerischen Mitglieder der ständigen Impfkommission (STIKO). Schwerpunkte der Arbeit der LAGI sind u. a. die Identifizierung von Impfhindernissen und gemeinsame Erarbeitung von Lösungen, zielgruppenspezifische Öffentlichkeitsarbeit unter Einbindung der Zugangswege der Mitglieder, Vermittlung von aktuellem Impfwissen an Multiplikatoren, gemeinsame Erarbeitung einer für die Evaluation von Maßnahmen relevanten Datenlage.

Ergebnisse. Eine Vielzahl von gemeinsamen Publikationen, bayernweiten Impfaktionen, Fortbildungen und Kongresse haben die Bekanntheit und Akzeptanz von Impfungen in der bayerischen Bevölkerung gesteigert, die Impfsituation insbesondere bei Masern hat sich verbessert. Die LAGI hat sich auch beim Krisenmanagement zum GrippeimpfstoffVersorgungsengpass in der Saison 2012/13 bewährt. Die Ergebnisse der nachfolgenden gemeinsamen Evaluation führten zur Änderung des Ausschreibungsverfahrens der Kassen und innerhalb der LAGI zum zeitnahen Austausch von Daten der Kassen, der Kassenärztlichen Vereinigung, der Hausärzte und des Pharmazeutischen Großhandels.

Schlussfolgerung. Das Zusammenwirken aller für die Impfprävention wichtigen Akteure in einem Bundesland ist günstig für eine Verbesserung der Impfsituation.

\section{DGPI-PO-ER-8}

Neurotuberkulose durch Mycobacterium bovis mit vaskulitischer Encephalitis als Primärmanifestation

Cassel F.', Wurm D. ', Möller J.', Spüntrup E. ${ }^{2}$, Brinkmann F. ${ }^{3}$, Cedzich C. ${ }^{4}$ ${ }^{1}$ Klinikum Saarbrücken, Zentrum für konservative und operative Kinderund Jugendmedizin, Saarbrücken, ${ }^{2}$ Klinikum Saarbrücken, Institut für Radiologie, Saarbrücken, ${ }^{3}$ Medizinische Hochschule Hannover, Klinik für pädiatrische Pneumologie, Allergologie und Neonatologie, Hannover, ${ }^{4}$ Klinikum Saarbrücken, Klinik für Neurochirurgie, Saarbrücken

Fallbericht. Ein 2 7/12 Jahre altes Mädchen präsentiert sich mit seit einigen Tagen bestehender Übelkeit und Erbrechen sowie wechselnder, jedoch zunehmender Schläfrigkeit und Teilnahmslosigkeit.

Ergebnisse. Die LP ergab 161/3 Zellen, 51 mg/dl Eiweiß und $34 \mathrm{mg} / \mathrm{dl}$ Glucose. In einem cMRT zeigte sich eine entzündliche Meningoencephalitis ohne Diffusionsstörung. Es erfolgte zunächst eine antibakterielle, antivirale und tuberkulostatische Therapie. Die Liquorkultur und die PCR ergaben keinen Erregernachweis. Der Tuberkulintest, der IGRA und ein Röntgen-Thorax waren unauffällig. Bei einer serologisch nachweisbaren akuten Mykoplasmeninfektion erfolgte die Therapie mit Steroiden und es kam zu einem kompletten Verschwinden der Symptomatik. Im Verlauf trat eine akute neurologische Verschlechterung mit cerebralen Anfällen und einem SIADH auf. Im MRT zeigten sich weiterhin entzündliche Veränderungen mit nun rundlichen leptomeningealen KM-Anreicherungen und einem vaskulitischen Mediateilinfarkt im nicht entzündlich veränderten Bereich. Die LP ergab 496/3 Zellen, $14 \mathrm{mg} / \mathrm{dl}$ Glucose und ein erhöhtes Laktat. Im Referenzzentrum für Mykobakterien gelang aus je $10 \mathrm{ml}$ Liquor und Magensaft per PCR und kulturell der Nachweis von M. bovis in beiden Proben. Der IGRA und der Hauttest waren weiterhin negativ. Unter tuberkulostatischer Therapie kam es zu einem malresorptiven Hydrocephalus und ausgeprägten psychomotorischen Ausfällen.

Schlussfolgerung. Der Fall zeigt den dramatischen Verlauf einer Neurotuberkulose, nach Übertragung von M. bovis von Mensch zu Mensch, ohne Primärsymptome. Zudem ist der Nachweis von Mykobakterien aus gängigen Mengen Liquor schwierig. Bei entsprechenden klinischen Symptomen und passendem Liquorbefund sollte trotz negativer PCR und Liquorkultur an eine tuberkulöse Meningitis gedacht und therapiert werden. 


\section{DGPI-PO-ER-9}

\section{ZNS-Tuberkulose - ungewöhnlicher Verlauf und Therapieansatz}

Jochim J.', Klepzig M.', von Spreti E.', Rose M.A. ${ }^{\prime}$

'Sana-Klinikum, Klinik für Kinder- und Jugendmedizin, Offenbach

Einleitung. ZNS-Tuberkulosen präsentieren sich klassisch als Haubenmeningitis, bei Immunsupprimierten auch im Rahmen der Generalisation. Wir schildern einen schwierigen Fall und diskutieren die Thalidomid Therapie bei Tuberkulomen.

Kasuistik. Neunjähriges pakistanisches Mädchen mit Husten, Nachtschweiß und Fieber; unter tuberkulozider Vierfachtherapie gutes Ansprechen. Im Verlauf Wiedervorstellung mit zerebralem Krampfanfall, in Bildgebung unklare Raumforderung, unter erneute Kombinationstherapie inklusive Steroiden mäßige Konsolidierung, nach erneuter Verschlechterung Therapiemodifikation (Gyrase-Hemmer, Antikonvulsiva, individueller Thalidomid-Heilversuch), hierunter depressive Symptomatik und protrahierte Restitutio ad integrum. Immunologische Abklärung unauffällig.

Diskussion. Auch ohne nachweisbare Abwehrschwäche kann es zu Tuberkulomen kommen, die eine therapeutische Herausforderung darstellen. Bei unserer Patientin lag ein Tuberkulostatika-Schnellmetabolismus vor; die interkurrente Depression (am ehesten im Rahmen der Gyrasehemmer-Therapie) sprach auf Antidepressiva an und sistierte mit Absetzen der Antibiose. Eine zu erwägende Thalidomid-Behandlung von Tuberkulomen erfolgt off-label und wird kontrovers diskutiert, stellt aber wie in unserem geschilderten Fall eine interessante und potentiell aussichtsreiche therapeutische Option dar.

Schlussfolgerung. Entzündliche Tuberkulome können unabhängig von ihrer Infektiosität durch mechanische Obstruktion (Atemwege) oder Druckausübung (Schädel) bedrohliche Komplikationen hervorrufen und sind durch klassische Tuberkulose-Medikamente schlecht zu beeinflussen. Neben invasiven Ablationstechniken kann unter Kontrazeption eine antiproliferative Thalidomid-Therapie erfolgreich eingesetzt werden.

\section{DGPI-PO-ER-10}

Weichteilabszess und Osteomyelitis des Humerus durch Mycobacterium bovis nach BCG-Impfung

Deckers M. ', Krause J.C. ', Teckentrup M. ', Seidl M. ${ }^{2}$, Schneider C. ${ }^{3}$, Hufnagel M. ${ }^{1}$, Henneke P. ${ }^{1,2}$

'Uniklinik Freiburg, Allgemeine Pädiatrie, Sektion für Pädiatrische Infektiologie und Rheumatologie, Freiburg, ${ }^{2}$ Centrum für Chronische Immundefizienz, Freiburg, ${ }^{3}$ Universitätsklinikum Freiburg, Institut für Medizinische Mikrobiologie, Freiburg

Einleitung. Die Immunisierung mit Mycobacterium bovis (Bacille Calmette-Guerin; BCG) erfolgt bei Neugeborenen nach Empfehlungen der WHO in Ländern mit hoher Durchseuchung von Mycobacterium tuberculosis (TBC) und wird in Deutschland nicht mehr empfohlen. Trotz weltweit vielfach eingesetzter Impfung sind systemische Komplikationen bei Immunkompetenten selten.

Fallbericht. Ein 2 Jahre alter russischstämmiger Junge stellte sich mit einer abszedierenden Weichteilinfektion im Bereich des linken Oberarms und radiologisch gesicherter Osteomyelitis vor. Im Alter von 4 Tagen war in Russland eine BCG-Impfung (Impfstamm unklar) am linken Oberarm erfolgt. Keine relevanten Vorerkrankungen, die weiteren Immunisierungen nach russischem Impfkalender wurden gut vertragen. Ein Tuberkulin-Hauttest war mit einer Induration von $16 \mathrm{~mm}$ positiv, ein „Interferon- $\gamma$ Release Assay“ (Quantiferon") zeigte ein negatives Ergebnis. In der Knochenbiopsie waren epitheloidzellige Granulome und säurefeste Stäbchen nachweisbar. Im chirurgische Exzidat des Abszesses fiel eine M. tuberculosis complex n-PCR (IS 6110) positiv aus, kulturell konnte M. bovis BCG (Impfstamm) nachgewiesen werden. Phänotypisch, wie genotypisch war das Isolat empfindlich gegen Isoniazid, Rifampicin und Ethambutol und resistent gegen Pyrazin- amid. Daraufhin wurde eine Therapie mit Isoniazid, Rifampicin und Ethambutol für 6 Monate initiiert. Funktionelle In-vitro-Tests zeigten eine regelrechte Bildung von Interferon- $\gamma$ und IL-12p4o auf verschiedene endogene und mikrobielle Liganden inklusive IL-12, IFN- $\gamma$ und einen BCG-Impfstamm.

Schlussfolgerung. Eine BCG-Osteomyelitis bzw. -Weichteilinfektion muss bei BCG-geimpften Neugeborenen sowie Symptombeginn $<4$ Jahre nach Impfung und fehlendem TB-Kontakt erwogen werden.

\section{DGPI-PO-ER-11}

\section{Pulmonale Infektion durch S. aureus unter Infliximab-Therapie} eines Morbus Crohn

\section{Schöndorf D. ${ }^{1}$, Hennes P. ${ }^{1}$, Rentz K. ${ }^{2}$, Herrmann M. ${ }^{3}$, Schneider G. ${ }^{4}$,} Rohrer T.', Gortner L.'

'Universitätsklinikum des Saarlandes, Klinik für Allgemeine Pädiatrie und Neonatologie, Homburg, ${ }^{2}$ Universitätsklinikum des Saarlandes, Klinik für Innere Medizin V - Pneumologie, Homburg, ${ }^{3}$ Universitätsklinikum des Saarlandes, Institut für Medizinische Mikrobiologie und Hygiene, Homburg, ${ }^{4}$ Universitätsklinikum des Saarlandes, Klinik für Diagnostische und Interventionelle Radiologie, Homburg

Kasuistik. Rezidivierende perianale Fisteln und Abszesse bei Durchfall und Gedeihstörung führten bei einem 10-Jährigen zur Diagnose eines M. Crohn. Abgesehen von nichtstenosierender jejunaler und ilealer Inflammation keine weitere Manifestation. Induktion einer anhaltenden Erstremission mittels eines Kurses Prednisolon, gefolgt von Infliximab. Aufgrund mehrerer Episoden von Bauchschmerz und Durchfall je 2 Wochen vor der nächsten Gabe Verkürzung des Intervalls der Infliximab-Infusionen von 8 auf 6 Wochen ab 23. Zyklus, worunter erneute Beschwerdefreiheit. Mit 14 Jahren (32. Zyklus) im Routine-Röntgen Verdacht auf Rundherd des rechten Unterlappens. Laborchemisch und funktionell (TB-IGRA, ACE, Durchflusszytometrie, CGD-Test, Immunglobuline, Schweißtest, Echokardiographie, Lungenfunktion) unauffällige Befunde, CT und MRT weder initial noch im Verlauf wegweisend. Bronchoskopisch gerötete Mukosa und Eiter in Segment 9 rechts, im Aspirat isoliert kultureller Nachweis eines Methicillin-sensiblen $S$. aureus, in der Lavage segmentkernig-granulozytäres Zellbild ohne Spezifität im Sinne Crohn-Manifestation. Antibiotische Therapie mit Flucloxacillin und Fosfomycin unter Fortsetzung des Infliximabs. Nie bronchopulmonale Symptome, ebenso keine Hinweise auf intestinale Aktivitätszunahme des Crohn.

Schlussfolgerung. Etabliert in der Therapie des perianalen Crohns ist wenig zu bakteriellen pulmonalen Infektionen unter Infliximab (außer M. tuberculosis, S. pneumoniae, Legionella pneumophila) beschrieben. Die eitrige pulmonale Infektion des Patienten war anhaltend asymptomatisch und diagnostischer Endpunkt eines Zufallsbefundes. Das Infektions-Monitoring einer Infliximab-Therapie bleibt eine Herausforderung, insbesondere auch in Anbetracht der Differenzialdiagnose bronchopulmonale Crohn-Manifestation.

\section{DGPI-PO-ER-12}

Chronische Pleuritis und persistierender rechtsseitiger Pleuraerguss bei Chlamydia-pneumoniae-Infektion

Schmidt S.M.', Bruns R. ', Beyersdorff A. ', Otto S. ${ }^{2}$, Radmann R. ${ }^{3}$, Lode H. 'Universitäts-Kinderklinik, Greifswald, ${ }^{2}$ Universitäts-Klinik für Radiologie, Greifswald, ${ }^{3}$ Asklepios Klinik, Klinik für Kinderheilkunde, Pasewalk

Kasuistik. 17-jährige Patientin, rechtsthorakal und in der Schulter Schmerzen begleitet von einem trockenem unproduktiven Husten. Sonographisch und röntgenologisch rechtsseitiger Pleuraerguss; Amoxicillin und Klacid für 2 Wochen. Danach annähernd beschwerdefrei. Im Oktober 2012 fieberhafte purulente Angina tonsillaris und erneut rechtsthorakal Schmerzen; Amoxicillin 10 Tage. Sonographisch un- 
verändert geringer Pleuraerguss. Daraufhin Vorstellung in unserem Hause.

Ergebnisse. Pleurapunktion: Exsudat (Eiweiß $>3$ g/l; Pleura-Eiweiß/ Serum-Eiweiß >0,5; Pleura-LDH/Serum-LDH >0,6; Serum-Albumin/ Pleura-Albumin 1,2 g/dl). Keine maligne Zell-Populationen oder autoimmunologische Erkrankung. Kein Trauma, kein Hinweis auf onkotisch-hydrostatische oder vaskuläre Ätiologie. Thorax-CT im rechten Mittellappen narbige und im rechten Unterlappen dystelektatischkonsolidierende konfluierende Parenchymveränderungen mit kleiner Traktionsbulla -infektiöses Geschehen, keine Lungenarterienembolie, kein malignes Geschehen. Ausschluss Tuberkulose (Hauttest nach Mendel-Mantoux, Quantiferon, Elispot, Kultur). In der BAL und im Pleurapunktat Nachweis von Chlamydia pneumoniae. Daraufhin Doxycyclin i.v. über 14 Tage und 2 Zyklen Azithromycin. Keine komplette Rückbildung des Ergusses. Erneute Beschwerden, Pleuraerguss wieder zunehmend $(11 \mathrm{~mm})$. Nochmalig Ofloxacin. Leichte bronchiale Hypereagibilität, deshalb Budesonid inhalativ für 3 Monate. Milde anti-inflammatorische Therapie mit Ibuprofen. Nach 3 Monaten Pleuraerguss rückläufig ( $7 \mathrm{~mm})$. Intensive Physiotherapie. Nach weiteren 3 Monaten nahezu komplette Rückbildung.

Schlussfolgerung. Eine persistierende Chlamydia-pneumoniae-Infektion wird häufig bei Kindern mit rezidivierender oder chronischer Bronchitis gefunden. Sie kann auch bei einem chronischen Pleuraerguss gefunden werden.

\section{Infektionen bei immundefizienten Patienten}

\section{DGPI-PO-II-1}

Validation of the suitability of Lophius Biosciences T-Track ${ }^{\circledR}$ CMV to assess the functionality of cell-mediated immunity (CMI) in hemodialysis patients

Banas B. ${ }^{1}$, Böger C. ${ }^{1}$, Lückhoff G. ${ }^{2}$, Krüger B. ${ }^{3}$, Starke A. ${ }^{4}$, Bendfeldt H. ${ }^{4}$, Batzilla J. ${ }^{4}$, Köstler J. ${ }^{5}$, Barabas S. ${ }^{4}$, Wagner R. ${ }^{5}$, DemI L. ${ }^{4}$, Leicht J.L. ${ }^{6}$, Krämer B.K. ${ }^{3}$

'University Medical Center Regensburg, Department of Internal Medicine II, Regensburg, ${ }^{2}$ Dialysis Center, Landshut, ${ }^{3}$ University Medical Center Mannheim, ${ }^{5}$ th Department of Medicine, Mannheim, ${ }^{4}$ Lophius Biosciences, Regensburg, ${ }^{5}$ University Regensburg, Institute of Medical Microbiology and Hygiene, Regensburg, ${ }^{6}$ Dialysis Center, Schwandorf

Objective. Inadequate impairment of cytomegalovirus(CMV)-specific cell-mediated immunity (CMI) by immunosuppressive therapy is a major cause for CMV reactivations and associated complications in solid organ transplantation. Thus, assessing the function of CMV-specific CMI may help to predict the onset of complications and to individually adjust immunosuppressive as well as antiviral therapy. The novel diagnostic tool T-Track ${ }^{\circledast} \mathrm{CMV}$ allows the simultaneous detection of CMVreactive T-helper- and cytotoxic T-cells as well as NK- and NKT-cells. The aim of this cross sectional multicenter study was to evaluate the suitability of T-Track ${ }^{\oplus} \mathrm{CMV}$ for assessing the CMV-specific CMI in a clinically relevant pre-transplant patient population.

Methods. Test sensitivity and specificity for T-Track ${ }^{\circledR} \mathrm{CMV}$ were examined in a cohort of 124 hemodialysis patients of whom 67 (54\%) revealed a CMV positive serostatus. T-Track ${ }^{\star} \mathrm{CMV}$ results were compared with Quantiferon-CMV and a cocktail of 6 preselected CMV tetramers as reference tests.

Results. Positive T-Track ${ }^{\circledR}$ CMV results were obtained in $60 / 67$ (sensitivity $89.6 \%$ ) of CMV-seropositive patients. Low, however significant numbers of IE-1- but not pp65-reactive cells were observed in 12 of 57 $\mathrm{CMV}$-seronegative dialysis patients. For comparison, the reference tests Quantiferon-CMV and CMV tetramer cocktail revealed sensitivities of $72.6 \%(45 / 62)$ and $76.9 \%(40 / 52)$, respectively.

Conclusion. T-Track $\mathrm{CMV}^{\circledast}$ can be used in a broad population of hemodialysis patients independent of their HLA-type. Thus, T-Track ${ }^{\oplus}$ CMV assay may also represent a valuable tool to assess functionality of CMVspecific CMI in transplant recipients and help to guide personalized antiviral and immunosuppressive therapy.

\section{DGPI-PO-II-2}

SeptiFast Multiplex ${ }^{\oplus}$-PCR im Vergleich zur Blutkultur bei Kindern und Jugendlichen unter Antibiotika-Therapie mit Verdacht auf eine systemische Infektion

Dohna-Schwake C.', Gies F.', Tschiedel E.', Felderhoff-Müser U.', Steinmann J. ${ }^{2}$, Rath P.-M. ${ }^{2}$

'University of Duisburg-Essen, Pediatrics, Essen, ${ }^{2}$ University of DuisburgEssen, Institut für Medizinische Mikrobiologie, Essen

Hintergrund. Die diagnostische Wertigkeit von Multiplex-PCR-Systemen zur Identifikation von Bakterien und Pilzen bei Kindern mit Verdacht auf eine Infektion, die schon mit Antibiotika behandelt werden, ist unklar.

Methoden. In einer prospektiven Beobachtungsstudie wurden 39 Kinder (18 onkologisch, 10 nach Organ-Transplantation, 6 neuropädiatrisch, 5 allgemeinpädiatrisch), die die Kriterien eines Systemischen Inflammations-Syndroms (SIRS) erfüllten, gleichzeitig mittels Blutkultur und SeptiFast Multiplex-PCR untersucht. Primäres Zielkriterium war die Rate von positivem SeptiFast im Verhältnis zur Blutkultur. Für die Biomarker CrP, Procalcitonin und Leukozyten wurden Receiver-Operating-Curves mit Area under the curve AUC zur Diskrimination zwischen pos. und neg. SeptiFast erstellt.

Ergebnisse. 25 Kinder waren zum Zeitpunkt der Diagnostik auf der Intensivstation. Bei 14 Kindern konnte die bakterielle PCR von einem oder zwei Bakterien/Pilzen nachgewiesen werden, im Vergleich zu 4 positiven Blutkulturen $(\chi 2: \mathrm{p}=0,005)$. Nach klinischer Wertung wurden 12 PCR-Ergebnisse und zwei Blutkulturen als Infektion beurteilt $(\chi 2$ : $\mathrm{p}=0$,029). In 7 Fällen wurde die Therapie aufgrund des SeptiFast-Ergebnisses geändert, in 2 Fällen aufgrund der Blutkultur. ROC-Kurven zur Unterscheidung von positivem und negativem SeptiFast erbrachten folgende AUC: CrP 0,514; Leukozyten 0,464; Procalcitonin 0,838. Ein Procalcitonin-Wert von $0,89 \mathrm{ng} / \mathrm{ml}$ hat eine Sensitivität von 0,91 und eine Spezifität von 0,7 .

Schlussfolgerung. Bei Kindern mit SIRS unter Antibiotika-Therapie gelingt signifikant häufiger ein Keimnachweis mittels Multiplex-PCR im Vergleich zur Blutkultur. Der klinische Nutzen von SeptiFast ist bisher nicht endgültig zu belegen, kann aber unter besonderen Umständen (krankes Kind, mit Antibiotika vorbehandelt, hohes PCT) von Nutzen sein.

\section{DGPI-PO-II-3}

Seroprävalenz von Herpesviren (CMV; EBV, HSV) bei Erstdiagnose einer onkologischen Erkrankung im Kindes- und Jugendalter

Knorr M. ', Verheyen J. ${ }^{2}$, Trilling M. ${ }^{2}$, Fleischhack G. ${ }^{1}$

'Universitätsklinikum Essen, Pädiatrische Hämatologie/Onkologie, Essen, 2Universitätsklinikum Essen, Institut für Virologie, Essen

Fragestellung. Untersuchung der Seroprävalenz von Herpesviren bei Kindern mit Erstdiagnose einer malignen Erkrankung und Unterschiede nach Alter/Diagnose.

Material und Methoden. In einer retrospektiven Untersuchung wurden initiale virologische Daten aller pädiatrisch-onkologischen Patienten, die in den Jahren 2010 bis 2013 in unserem Zentrum behandelt wurden, analysiert. Eingeschlossen wurden Patienten, die in unserem Zentrum erstdiagnostiziert wurden, eine abgeschlossene Polychemotherapie erhielten und bei denen die virologische Diagnostik vor Start der Chemotherapie in der lokalen Virologie durchgeführt wurde.

Ergebnisse. Es wurden 252 Patienten ausgewertet (männlich 58\%, n=146 /weiblich $42 \%, n=106$ ). Die Seroprävalenz über alle Altersgruppen lag für CMV bei $45 \%$, die Seroprävalenz für EBV bei $54 \%$ und die Seroprä- 
valenz für HSV bei $41 \% .62 \%$ der Patienten sind für einen oder mehrere der o. g. Viren seropositiv. 28\% der Patienten sind für 1 der o. g. Herpesviren seropositiv, $22 \%$ für 2 der 0 . g. Herpesviren seropositiv, $12 \%$ für alle o. g. Herpesviren seropositiv.

Schlussfolgerung. Die vorgestellten Daten stellen die Prävalenz in unserem Zentrum dar und sind limitiert durch die monozentrische Untersuchung und die kleine Fallzahl. Sie zeigen, dass ein großer Teil der Patienten latent mit den oben untersuchten Herpesviren infiziert sind. Die Auswertung nach Alter bzw. Grunderkrankung ist aufgrund der kleinen Fallzahlen sehr inhomogen. Multizentrische Untersuchungen sind notwendig, um signifikante Daten hinsichtlich Prävalenz nach Alter und Diagnosen zu erhalten. Die Daten wurden erhoben, um eine prospektive Studie über Herpesvirusinfektionen und -reaktivierung bei kinderonkologischen Patienten mit Fieber in Neutropenie nach Chemotherapie vorzubereiten.

\section{DGPI-PO-II-4}

A pilot study in kidney transplant recipients to assess the suitability of activated BZLF1 for the monitoring of EBV-specific cellular immunity

\section{DemI L. ${ }^{1,2}$, Barabas S. ${ }^{1,2}$, Zeman F. ${ }^{3}$, Bendfeldt H. ${ }^{1}$, Starke A. ${ }^{1}$, Pfister A. ${ }^{2}$,} Krüger B. ${ }^{4}$, Jilg W. ${ }^{2}$, Wolf H. ${ }^{2}$, Koller M. ${ }^{3}$, Krämer B.K. ${ }^{4}$, Banas B. ${ }^{5}$

${ }^{1}$ Lophius Biosciences, Regensburg, ${ }^{2}$ University Medical Center Regensburg, Institute for Medical Microbiology and Hygiene, Regensburg, ${ }^{3}$ University Medical Center Regensburg, Center for Clinical Studies, Regensburg, ${ }^{4}$ Medical Faculty Mannheim of the University of Heidelberg, Mannheim, ${ }^{5}$ University Medical Center Regensburg, Department of Internal Medicine II, Regensburg

Objectives. In immunocompetent individuals, Epstein-Barr virus (EBV) infections are effectively controlled by cell-mediated immunity (CMI). Impairment of CMI by immunosuppressive therapy occasionally causes EBV-reactivation which can be associated with clinical complications i.e. PTLD. The aim of the pilot study in renal transplant recipients was to evaluate activated (a)BZLF1 to assess the functionality of BZLF1-reactive effector cells in the course of immunosuppressive treatment. Herein, (a)BZLF1 reveals the unique property to stimulate a broad spectrum of antigen-reactive effector cells.

Methods. We performed a two year prospective observational study in a cohort of 83 renal transplant recipients, of whom $92.8 \%$ revealed a positive EBV serostatus. Blood was collected pre- and at different time points post transplantation. Functional BZLF1-reactive $\mathrm{T}$ cells were quantified applying (a)BZLF1 as stimulator antigen combined with IFN- $\gamma$ ELISpot. EBV load was determined using quantitative PCR.

Results. Prior to transplantation, a significant (a)BZLF1-reactive CMI was detected in $60.9 \%$ of EBV-seropositive patients followed by a substantial decrease in the first three weeks post transplantation. In some patients, reactive cells started to recover in month 6 to 18 reaching in part maximum levels exceeding even those observed prior to immunosuppression. Transient, clinically inapparent EBV-reactivation was observed in $53 \%$ of the patients. Analysis of individual patient courses revealed that EBV-reactivations occurred preferentially at times with low numbers of (a)BZLF1-reactive cells.

Conclusion. Monitoring of functional (a)BZLF1-reactive CMI may be an interesting novel strategy to assess the risk for EBV-reactivation in immunocompromised transplant recipients.

\section{DGPI-PO-II-5}

Stimulation of protein-reactive effector cells by activated antigens: a novel strategy for monitoring cell mediated immunity

Barabas S. ${ }^{1,2}$, Spindler T.', Widmann T.', Tonar C. , Bendfeldt H. ', DemI L., ${ }^{1,2}$

${ }^{1}$ Lophius Biosciences, Regensburg, ${ }^{2}$ University of Regensburg, Institute for Medical Microbiology and Hygiene, Regensburg

Suppression of cell mediated immunity (CMI) may cause serious clinical complications including microbial infections and reactivations. Thus, accurate quantification and monitoring of functional effectors of CMI may allow reliable prediction, detection and personalized treatment strategies. We have developed a novel methodology for the functional analysis of CMI based on the combined application of acitvated herpes virus-derived stimulator antigens and the highly sensitive ELISpot technology. Activated proteins reveal the unique capacity to stimulate a broad spectrum of clinically relevant effector cells including T helper and cytotoxic T cells as well as NK and NKT cells. The activation of proteins mediates the translocation to the exogenous and endogenous processing pathway of APC for epitope-loading on MHC-I in addition to MHC-II molecules by cross-presentation. Stimulation of peripheral blood mononuclear cells (PBMC) with preselected activated CMV-proteins reveal a clinical sensitivity above $90 \%$ independent of the subject's HLA composition. Assay performance is highly reproducible with variability values less than $25 \%$ and a linear correlation between the amount of reactive cells and total PBMC counts. Thus, activated stimulator antigens in combination with ELISpot technology represent a promising strategy to assess the immune status of immunosuppressed patients.

\section{DGPI-PO-II-6}

\section{Fallbericht: autoimmune Neutropenie des Kindesalters}

\section{Rupietta M.', Rühmer P. ${ }^{2}$}

'Klinikum St. Georg gGmbH/Klinik für Kinder- und Jugendmedizin, Pädiatrische Rheumatologie, Infektiologie und Immunologie, Leipzig, ${ }^{2} \mathrm{HELIOS}$ Vogtland-Klinikum Plauen, Klinik für Kinder- und Jugendmedizin, Plauen

Wir berichten über einen 8 Monate alten Säugling, der uns von einem externen Krankenhaus mit schweren Weichteilinfektionen eingewiesen wurde. Auswärts waren zunächst Fieber und ein Abszess am Oberschenkel aufgetreten, der unter antibiotischer Therapie rasch ausheilte. Drei Wochen später kam es zu einer Verschlechterung des Allgemeinzustandes mit Fieber bis $40^{\circ} \mathrm{C}$ und einem oberflächlichen Hautdefekt am Skrotum. Es zeigten sich deutlich erhöhte Entzündungswerte und eine erneute intravenöse antibiotische Therapie wurde eingeleitet. Im Wundabstrich wurde Pseudomonas aeruginosa nachgewiesen. Trotz Therapie entwickelte der Patient eine schwere Balanoposthitis und einen Skrotalabszess, die eine operative Sanierung nötig machten. Nach Besserung der Wundverhältnisse und Entlassung kam es wenige Tage später erneut zum Anstieg der Entzündungsparameter bei Hinweisen auf eine phlegmonöse Ausbreitung in beide Leistenregionen. Nach Verlegung in unsere Klinik führten wir eine umfangreiche Immundefektdiagnostik durch. Die schwere Infektion konnte durch eine gezielte antibiotische Therapie und intensivierte Wundpflege beherrscht werden. Im Verlauf zeigten sich dauerhaft unter $0,4 \mathrm{Gpt} / \mathrm{l}$ erniedrigte neutrophile Granulozyten, beweisend für eine schwere, chronische Neutropenie. Eine Knochenmarkpunktion ergab eine ungestörte Granulopoese, während in der Autoimmundiagnostik Antikörper für Human Neutrophil Antigen hochtitrig nachgewiesen werden konnten. Unter der Diagnose einer autoimmunen (benignen) Neutropenie des Kindesalters umfassen die Therapieoptionen, neben einer antibiotischen Dauerprophylaxe, die Gabe von Immunglobulinen oder G-CSF bis zur Remission der Erkrankung. 
DGPI-PO-II-7

\section{Rotavirus-Impfung weist Weg zum SCID}

Schmidt M. ', Wegner M. ', Zimmermann K. ${ }^{2}$, Grunwald U. ${ }^{3}$, Lode H. ${ }^{\prime}$, Bruns R. ${ }^{\prime}$ ${ }^{1}$ Universitätsmedizin Greifswald, Zentrum für Kinder und Jugendmedizin, Greifswald, ${ }^{2}$ Universitätsmedizin Greifswald, F.-Loeffler-Institut für Medizinische Mirkobiologie, Greifswald, ${ }^{3}$ Universitätsmedizin Greifswald, Inst. für Klin.Chemie, Greifswald

Einleitung. Seit August 2013 wird die Rotavirus-Impfung durch die STIKO empfohlen. Der orale Lebendimpfstoff wird ab einem Alter von 6 Wochen in 2 bzw. 3 Dosen verabreicht.

Kasuistik. Ein vier Monate alter Säugling wird mit Enteritis vorgestellt. anamnestisch Geburt mit $2330 \mathrm{~g}$, danach gute Gewichtsentwicklung, atopisches Ekzem bei familiärer Disposition, Mundsoor, Impfstatus vollständig einschließlich 2-maliger Rotavirusimpfung. Labordiagnostik: Leukopenie mit Lymphozytopenie $(1,6 \mathrm{Gtp} / \mathrm{l})$, normales Differenzialblutbild, kein CRP; im Stuhl wird Rotavirus-Ag-Nachweis.

Verlauf. Nach Stabilisierung erfolgt die Entlassung. Wiederaufnahme drei Wochen später mit stagnierendem Gewicht und einem dünnen Stuhl pro Tag. Labor: Erneut Lymphozytopenie (minimal o,6o) bei ansonsten normalen Standardwerten, weiterhin Rotavirus-Ag-Nachweis (Impfstamm) im Stuhl. Erweiterte Diagnostik mit erhöhter LDH $(11,3 \mu \mathrm{katal} / \mathrm{l})$, sowie erniedrigte IgA- (<o,o8 g/l) und IgG- (o,6 g/l) Spiegel bei normalen IgM-Werten. Die Durchflusszytometrie war mit fehlenden T- und NK-Zellen, jedoch nachweisbaren B-Zellen wegweisend für die Verdachtsdiagnose eines B+, T-, NK-SCID („severe combined immunodeficiency“).In Folge pulmonale Verschlechterung des Patienten, deshalb erweiterte antimikrobielle Therapie, weiterhin Einleitung der HLA-Typisierung und Verlegung zur Knochenmarktransplantation. Die als atopisches Ekzem interpretierten Hauterscheinungen können im Kontext des SCID auch als eine GvHD der maternalen T-Zellen gewertet werden.

Schlussfolgerung. Bei persistierender Rotavirusausscheidung über Wochen sollte differenzialdiagnostisch an einen Immundefekt gedacht werden.

\section{DGPI-PO-II-8 \\ Fatale CMV-Infektion bei einem Jungen mit MHC-II-Defizienz auf- grund homozygoter RFX5-Mutation}

Weise S.', Merkenschlager A. ', Liebert U.G. ${ }^{2}$, Sack U. ${ }^{3}$, Schwarz K. ${ }^{4}$, Lorenz M.R.', Bernhard M.K.', Siekmeyer M.', Schuster V.', Syrbe S. ${ }^{1}$

${ }^{1}$ Klinik und Poliklinik für Kinder- und Jugendliche, Universität Leipzig, Leipzig, ${ }^{2}$ Institut für Virologie, Universität Leipzig, Leipzig, ${ }^{3}$ Institut für klinische Immunologie, Universität Leipzig, Leipzig, ${ }^{4}$ Institut für Transfusionsmedizin, Universität Ulm, Abteilung Molekulare Diagnostik, Molekulare Therapie und Experimentelle Transplantation, Ulm

Fragestellung. Ausländische Patienten mit Heilungswunsch bei ungeklärten Grunderkrankungen stellen eine zunehmende Herausforderung an deutschen Kinderkliniken dar. Hieraus kann sich eine Diskrepanz zwischen Anspruch und therapeutischen Möglichkeiten ergeben. Wir berichten exemplarisch über den Krankheitsverlauf eines libyschen Säuglings mit komplexer Entwicklungsretardierung und Verdacht auf Immundefekt.

Methoden und Ergebnisse. Ein 10 Monate alter Junge wurde durch seine libysche Familie in unserer Klinik zur Diagnostik vorgestellt. Seit den ersten Lebensmonaten war er durch vermehrte Infektionen und eine komplexe neurologische Entwicklungsstörung unklarer Ursache in mehreren nordafrikanischen Krankenhäusern betreut worden. Bei Verdacht auf Immundefekt wurde er durch die Eltern mit dem Wunsch nach Heilung durch Stammzelltransplantation nach Deutschland verbracht. Die immunologische Phänotypisierung erbrachte einen kombinierten Immundefekt bei vollständigem Fehlen von MHC-IIMolekülen. Als Ursache der MHC-II-Defizienz fand sich eine bisher unbekannte homozygote Mutation im RFX5-Gen (c.150+2 T>C). Bei fortgeschrittener chronischer CMV-Infektion mit Enzephalitis bestand keine kurative Option durch Stammzelltransplantation. Der Junge verstarb im Rahmen der systemischen CMV-Infektion nach Entwicklung einer Ganciclovir-Resistenz.

Diskussion. Wir präsentieren einen Fall eines Bare-Lymphocyte-Syndroms aufgrund einer neuen homozygoten RFX5-Mutation als Ursache der MHC-II-Defizienz. Neben immunologischen Besonderheiten diskutieren wir ethische Aspekte der palliativen Versorgung ausländischer Patienten.

\section{DGPI-PO-II-9}

Ist die Diagnose sicher? - Aspergillus-Pneumonie unter Immunsuppression

Huber S. ', Kietz S. ', Lode H. ${ }^{\prime}$, Otto S. ${ }^{2}$, Bruns R. ${ }^{1}$

'Universitätsmedizin Greifswald, Klinik und Poliklinik für Kinder- und Jugendmedizin, Greifswald, ${ }^{2}$ Universitätsmedizin Greifswald, Institut für diagnostische Radiologie und Neuroradiologie, Greifswald

Einleitung. Aspergillus spp. gehören zur Gattung der Schimmelpilze und kommen ubiquitär vor. Sie können verschiedene Krankheitsbilder hervorrufen, u. a. führen sie im Rahmen invasiver Erkrankungen häufig zu einer pulmonalen Aspergillose mit Ausbreitung ins ZNS. Die Übertragung erfolgt meist aerogen über den Respirationstrakt. Besonders gefährdet sind immunsupprimierte, granulozytopene Patienten.

Kasuistik. Anamnese: Wir berichten über ein 8-jähriges russisches Mädchen mit einer HR-AML (ED 02/2013). Bereits seit 04/2013 leidet die Patientin unter rezidivierenden Fieberschüben und im auswärtigen Thorax-CT: V. a. pulmonale Pilzinfektion. Es wurde eine antimykotische Behandlung mit Voriconazol begonnen. Sechs Monate später erfolgte die Einreise nach Deutschland zur Rezidivtherapie. Laborbefunde bei Aufnahme: $\mathrm{CrP}$ 26omg/l. Klinisch kein Anhalt für Infektion. ThoraxCT (HR): in beiden Lungen multiple rundliche Läsionen, vereinbar mit einer Pilzpneumonie.

Therapie und Verlauf. Unter der Annahme einer invasiven Aspergillose erfolgte eine kalkulierte antimykotische Therapie mit Amphotericin B für 2,5 Monate. Danach wurde die Therapie auf Voriconazol umgestellt. Ein mikrobiologischer Erregernachweis gelang nicht. Im Verlauf zeigte sich laborchemisch und bildmorphologisch eine Befundbesserung. Diskussion. Bei immuninsuffizienten Personen kann Aspergillus spp. zu schweren rezidivierenden bzw. persistierenden pulmonalen Infektionen führen. Jedoch dürfen andere Erreger und Ursachen nicht außer Acht gelassen werden. Deshalb ist der mikrobiologische Erregernachweis immer anzustreben.

Schlussfolgerung. Es werden radiomorphologische Befunde, klinisches Vorgehen und mögliche Therapieoptionen bei immuninsuffizienten Patienten mit unklarer Erhöhung der Akute-Phase-Proteine diskutiert.

\section{DGPI-PO-II-10}

Invasive Aspergillose durch einen Triazol-resistenten Aspergillus fumigatus bei einem Jungen mit septischer Granulomatose

Möller J.C. ', Lander F. ', Kühl J.S. ${ }^{2}$, Roesler J.'

${ }^{1}$ Klinik und Poliklinik für Kinder- und Jugendmedizin, Universitätsklinikum Carl Gustav Carus, TU Dresden, Dresden, ${ }^{2}$ Charité-Universitätsmedizin Berlin, Klinik für Pädiatrie mit Schwerpunkt Onkologie und Hämatologie, Berlin

Fallbericht. Ein 10-jähriger Patient mit septischer Granulomatose unter Prophylaxe mit Itraconazol und Cotrimoxazol gab bei einer Routinekontrolle rechtsseitige Thoraxschmerzen seit einem Monat an. Radiologisch zeigte sich eine paramediane Raumforderung mit Invasion des oberen Mediastinums und der Pleura.

Therapie und Verlauf. Bei Verdacht auf Aspergillose erfolgte eine thorakoskopische Biopsie und anschließend Beginn der antimykotischen Therapie mit Voriconazol und Caspofungin. Im Biopsiematerial konn- 
ten keine Pilze nachweisen werden. Bei klinischer Besserung wurde daher nach 2 Wochen auf Voriconazol oral umgestellt. Etwa 2 bis 3 Wochen später kam es zu einer deutlichen Verschlechterung mit Fieber, Schwellung rechts thorakal und Schmerzen in Schulter und Arm. Es erfolgte eine erneute offene Biopsie. Die antimykotische Therapie wurde auf Amphotericin B und Caspofungin umgestellt. Diesmal wurde Aspergillus fumigatus mit einer hohen MHK für Itraconazol und Voriconazol nachgewiesen. Die antimykotische Therapie wurde über mehrere Monate fortgesetzt. Nach 3 Monaten wurde Caspofungin gegen Posaconazol oral getauscht. Der Herd war im Verlauf nur gering regredient, sodass der Patient schließlich einer allogenen Stammzelltransplantation mit einer intensitätsreduzierten Konditionierung und Granulozytentransfusionen zugeführt wurde. Nach der Transplantation kam es zur Regredienz des Befundes am Thorax.

Diskussion. Trotz Prophylaxe mit Itraconazol kam es zu einer lebensbedrohlichen Infektion durch Aspergillus fumigatus. Selbst unter langfristiger, kombinierter antimykotischer Therapie konnte keine Abheilung erreicht werden. Daher sollte eine Stammzelltransplantation als kurative Therapie der septischen Granulomatose schon frühzeitig in Erwägung gezogen werden.

\section{DGPI-PO-II-11}

\section{Fataler Verlauf einer Sepsis durch HSV-1 mit Multiorganversagen bei einem 15-jährigen Mädchen mit Morbus Hodgkin}

\section{Tschiedel E.', Brummel B. ${ }^{2}$, Dohna-Schwake C. ${ }^{1}$, Bernbeck B. ${ }^{2}$, Schneider D.T. ${ }^{2}$}

'Universitätsklinikum Essen, Klinik für Kinderheilkunde II, Essen, ${ }^{2}$ Klinikum Dortmund gGmbH, Kinderonkologie, Dortmund

Hintergrund. Herpes simplex Typ 1 (HSV-1) kann schwere systemische Infektionen mit fatalem Verlauf verursachen. Dennoch sind bei Kindern mit onkologischen Erkrankungen ohne Stammzelltransplantation keine schweren HSV-1-Organinfektionen außerhalb des ZNS beschrieben worden, die Ursache für eine therapieassoziierte Mortalität waren. Fallbericht. Wir berichten über ein 15-jähriges Mädchen mit M. Hodgkin und einer fatal verlaufenen HSV-1-Erstinfektion: Die ersten beiden Chemotherapieblöcke (EuroNet-PHL-C1) wurden gut vertragen. Drei Tage nach Ende des 2. Blocks kam es zu einem CRP-Anstieg ohne Fokus. Es erfolgte eine Therapie mit Piperacillin/Tazobactam. Nach einer Woche wurde die antibiotische Therapie bei Leukopenie um Teicoplanin erweitert. An Tag 9 kam es zu einer dramatischen Verschlechterung mit Leberversagen, Kreislauf- und Ateminsuffizienz, Nierenversagen und Krampfanfällen. Ein MRT-Schädel war unauffällig. Außer einer leichten Mucositis zeigten sich keine Haut- oder Schleimhautläsionen. Die antibiotische Therapie wurde um Cotrimoxazol, Caspofungin und Aciclovir ergänzt, eine kontinuierliche Hämodialyse wurde begonnen. Es bestand intravasaler Volumenmangel mit schwerer Mikrozirkulationsstörung. Trotz massiver Volumen- und Katecholamintherapie konnte die Kreislaufsituation nicht dauerhaft beherrscht werden. Im Blut fanden sich $>1$ Mio. Kopien HSV-1-DNA/ml, so dass eine fulminante HSV-1-Sepsis mit konsekutivem Multiorganversagen als ursächlich für den dramatischen Verlauf angesehen werden muss.

Schlussfolgerung. Jede immunsuppressive Therapie prädisponiert für eine systemische HSV-1-Infektion und es muss mit einem fulminanten Verlauf einer Erstinfektion gerechnet werden. Eine Behandlung mit Aciclovir muss bei suspekten Befunden in Erwägung gezogen werden.

\section{DGPI-PO-II-12}

Qualitätssicherung einer Aminoglykosidtherapie bei onkologischen Kindern und Jugendlichen während Fieberepisoden

Oberkircher N. ', Krieter D. ${ }^{2}$, Hecker D. ${ }^{2}$, Dlugaiczyk J. ${ }^{2}$, Schick B. ${ }^{2}$, Graf N. ${ }^{1}$, Simon A.

'Universität des Saarlandes, Pädiatrie, Homburg, ${ }^{2}$ Universität des Saarlandes, HNO, Homburg

Fragestellung. Qualitätssicherungsstudie zum empirischen Einsatz von Gentamicin bei pädiatrisch-onkologischen Patienten mit febriler Neutropenie (FN). Evaluation eines neuen Dosierungsschemas $(250 \mathrm{mg} / \mathrm{m} 2$ KOF, max. $10 \mathrm{mg} / \mathrm{kg}$, max. $400 \mathrm{mg}$ ) als tgl. Einmalgabe. Untersuchung tubulotoxischer oder ototoxischer Nebenwirkungen.

Material und Methoden. Gentamicin wurde immer in Kombination (z. B. mit Pip/Taz) verabreicht. Monitoring: Spiegel 1 Stunde (Berg) und 8-10 Stunden (Tal) nach Gabe. MAG3-Nierenszintigraphie bei Therapiebeginn, Serum Krea und Cystatin C, Spontanurin auf Elektrolyte, Albumin und $\beta_{2}$-Mikroglobulin im Therapieverlauf. HNO: konventionelle Audiometrie und Hochton-DPOAE (bis $18 \mathrm{kHz}$ ).

Ergebnisse. Bei insges. 71 Genta-Zyklen (medianes Alter 9,4 Jahre; IQR 6-13,2) lag die mediane Einzeldosis bei $8 \mathrm{mg} / \mathrm{kg}$. Der angestrebte Bergspiegel $(10-20 \mathrm{mg} / \mathrm{L})$ wurde in $65 \%$ erreicht, $12 \%$ lagen über- und $23 \%$ unterhalb des Zielbereichs. Der Talspiegel lag bei 11\% über $2 \mathrm{mg} / \mathrm{L}$. Nur ein Patient hatte ein a priori erhöhtes Kreatinin.

Diskussion. Die von Ho KK et al. [1] eingeführte, in unserer Studie bei kinderonkologischen Patienten evaluierte Gentamicin-Dosis (250 mg/ m2) führt zu deutlich höheren Einzel (Tages-)Dosen als der bisherige Standard ( $5 \mathrm{mg} / \mathrm{kg}$ ). Die Mehrzahl der Patienten erreicht so den angestrebten Spitzenspiegel. Bei einem Teil der Patienten scheint eine Augmentierung der renalen Clearance vorzuliegen. Hinweise auf eine genuin durch das Aminoglycosid induzierte Oto- oder Nephrotoxizätät wurden nicht gefunden.

1. Ho KK et al (1995) Pharmacotherapy 15:754-764

\section{Seltene infektiologische Krankheitsbilder}

\section{DGPI-PO-SI-1}

Säuglingsbotulismus - eine vergessene Krankheit als infektiologischer Notfall

Keil A.', Seul R. ', Aschenbrenner J.', Lehn M.', Dorner M. ${ }^{2}$, Becker J.C.'

${ }^{1}$ Marien-Hospital Witten, Kinder- und Jugendklinik, Witten, ${ }^{2}$ Robert-KochInstitut, Zentrum für Biologische Gefahren und spezielle Pathogene, Berlin

Einleitung. Progrediente Muskelhypotonie und Obstipation beim Säugling können schnelles Handeln erfordern.

Fallbericht. Sechs Monate alter Säugling mit Trinkschwäche. Muttermilch bis 5. Lebensmonat, unter Formulanahrung zunehmende Obstipation. Entwicklung von Muskelhypotonie mit Kopfhebeschwäche, Ptosis, Heiserkeit, trockene Mundschleimhaut, tastbare Skybalae, lebhafte Muskeleigenreflexe.

Diagnostik. Labor: BGA pH 7,38, $\mathrm{HCO}_{3}-19,8$ mmol/l, BZ 55 mg/dl, Laktat 1,5 mmol/l. Normwerte für Blutbild, CRP, Elektrolyte, Leber-/Nierenwerte, TSH, $\mathrm{NH}_{3}$, Stoff wechselbasisdiagnostik; Urin: Keton $5 \mathrm{mg} / \mathrm{dl}$; mikrobiologische Stuhldiagnostik: negativ; MRT Schädel unauffällig; Abdomensonographie: hoch stehende Harnblase; Echokardiographie: unauffällig; LZ-EKG: fehlende Herzfrequenzvariabilität.

Spezialdiagnostik (RKI). Stuhl (anaerobe Kultur/PCR): Clostridium botulinum und Toxin Serotyp B, Serum (Tierversuch): Neurotoxin Serotyp B

Diskussion. Nach Aufnahme von C.-botulinum-Sporen entwickeln sich diese im Zökum des Säuglings zu Bakterien, die Neurotoxin bilden. Dieses blockiert irreversibel motorische und autonome Nervenendigungen. Aufgrund der Symptomkonstellation Obstipation, Muskelhypotonie und fehlender Herzfrequenzvariabilität erfolgte die Stuhl- 
untersuchung. Die Antitoxintherapie mit Pferdeserum wurde (nach Keimnachweis) komplikationslos durchgeführt. Antibiotische Therapie ist nicht empfohlen. Die Untersuchung möglicher Kontaminationsquellen (Teebeutel, Honig, Hunde-Kot und Staubsaugerbeutel) verblieb negativ, wie zumeist bei Säuglingsbotulismus.

Schlussfolgerung. Bei progredienter Muskelhypotonie und Obstipation sollte an Säuglingsbotulismus gedacht werden. Lähmungen und Beatmungspflichtigkeit über Monate drohen. Antitoxin aus Pferdeserum erscheint genauso effektiv wie humanes.

\section{DGPI-PO-SI-2}

\section{Salmonellose im Säuglingsalter - oder: Was macht der Waran im Kinderzimmer?}

Klepzig M.', Jochim J.', von Spreti E.', Rose M.A. ${ }^{\text {' }}$

'Sana Klinikum Offenbach, Klinik für Kinder und Jugendmedizin, Offenbach

Einleitung. Frühkindliche Gastroenteritis kann lebensbedrohlich verlaufen. Neben viraler Ätiologie müssen in doppelter Hinsicht „exotische Differenzialdiagnosen" berücksichtigt werden.

Kasuistik I. Ein zwei Wochen altes voll gestilltes Mädchen mit toxischer akuter Gastroenteritis. Bei bakterieller Sepsis werden überraschend Salmonellen, als Infektionsquelle häuslich gehaltene Reptilien nachgewiesen.

Kasuistik II. Sechs Wochen alter Junge mit unklarer bakterieller Sepsis, im Verlauf Gastroenteritis. Bei empirischem Antibiotikaregime Nachweis von Salmonellen, Zuordnung der häuslichen Reptilienhaltung. Diskussion. Junge Kinder, Immunsupprimierte und chronisch-kranke Personen sind besonders anfällig für Salmonellosen. Gemäß DGPI sollen in Familien mit Kindern unter fünf Jahren keine Reptilien als Heimtiere gehalten werden, bei jeglicher Haltung von Heimtieren muss strikte Hygiene erfolgen. Reptilien sind von Küche oder anderen Bereichen mit Lebensmittelzubereitung fernzuhalten. Keine Reinigung von Terrarien, Aquarien u. ä. im Küchenwaschbecken, ggf. gründliche Reinigung und Desinfektion der Badewanne. Umgang der Kinder mit den Tieren nur unter Aufsicht. Zur Risiko-Einschätzung sollten Reptilien regelmäßig tierärztlich untersucht werden. Jungtiere können sich bereits im Ei infizieren. Eine antibiotische Sanierung der Jungtiere ist nicht erfolgreich und fördert Multiresistenzen.

Schlussfolgerung. Die Zahl häuslich gehaltener Exoten nimmt auch in Deutschland zu - Reptilien sind keine Streicheltiere! Es ist vielen Menschen - auch in medizinischen Berufen - nicht bekannt, dass Reptilien bis zu 90\% Träger und Ausscheider von Salmonellen und damit Infektionsquellen sind. Kinderärzte sollen bei Beratungsgesprächen auf diese wichtige epidemiologische Erkenntnis hinweisen.

\section{DGPI-PO-SI-3}

Überleben nach Pantoea agglomerans - Sepsis bei einem 10 Tage alten Frühgeborenen

\section{Woerdehoff R.', Lengua Hinojosa P.', Naust B. ', Hillebrand G. ${ }^{1}$}

${ }^{1}$ Klinikum Itzehoe, Klinik f. Kinder- und Jugendmedizin, Itzehoe

Fallbericht. Frühgeborenes der 32. SSW. Initial problemloser Verlauf. Am 10. Lebenstag Zeichen der Sepsis, Nachweis von Pantoea a. in der Blutkultur, Anpassung der Therapie (Vancomycin und Meropenem) Im Verlauf Vollbild einer neonatalen Sepsis. Zeichen der Meningoenzephalitis mit pathologischem aEEG. Pantoea-Nachweis auch aus dem Wundabstrich eines PVK-Abszesses. Später Stabilisierung, Extubation. Eine klinische und entwicklungsneurolog. Kontrolle im Alter von 10 Monaten erbrachte normale Befunde.

Diskussion. Pantoea a. ist ein Umwelt- und Agrarkeim, der nur äußerst selten als Auslöser menschlicher Infektionen nachgewiesen wird, dann häufig als septische Arthritis oder Synovitis nach Penetrationsverletzungen. Bei Neonaten gibt es nur 18 Beschreibungen einer Sepsis durch Pantoea, zumeist fulminante Krankheitsverläufe mit septischen Schock, Thrombopenie und Lungenblutung trotz früher Therapie. Pantoea war auf die meisten Antibiotika in vitro gut sensibel, in vivo zeigte sich jedoch ein geringer Therapieerfolg. In der Literatur wird die Mortalität für systemische Infektionen mit $44 \%$ angegeben, bei Neonaten bis zu $88 \%$. Ausbrüche durch kontaminierte Infusionslösungen sind beschrieben. In unserem Fall vermuten wir eine Infektion über einen PVK. Die Umgebungsuntersuchung und Kultur der Infusionslösung erbrachte keinen Nachweis von Pantoea, weitere Fälle traten nicht auf. Schlussfolgerung. Pantoea a. ist ein seltener und aggressiver Erreger einer neonatalen Sepsis, die Verläufe sind gekennzeichnet durch hohe Mortalität. Überleben ohne Residuen unter frühzeitiger antibiotischer Therapie ist jedoch möglich. Der Nachweis des Keims sollte eine Umgebungsuntersuchung veranlassen. Neben kontaminierten Infusionslösung kommen auch „banale“ Eintrittspforten, z. B. PVK, in Betracht.

\section{DGPI-PO-SI-4}

\section{Sinusitis frontalis mit Weichteilschwellung und intrakraniellem Empyem}

\section{Weichert S. ${ }^{1}$, Nissen J. ${ }^{2}$, Tenenbaum T. ${ }^{1}$}

'Universitätsmedizin Mannheim, Klinik für Kinder- und Jugendmedizin, Mannheim, ${ }^{2}$ Universitätsmedizin Mannheim, Institut für klinische Radiologie und Nuklearmedizin, Mannheim

Fallbericht. Ein bisher gesundes 11 Jahre altes Mädchen stellte sich wegen einer rezidivierenden Sinusitis frontalis vor. Vorausgegangen war ein Krankenhausaufenthalt mit frontal betontem Kopfschmerz, fraglich unklarem Bewusstseinszustand und frontaler Weichteilschwellung. Unter dem Verdacht auf eine Sinusitis frontalis bei erhöhtem CRP (169 mg/l) Beginn einer antibiotischen Therapie mit Cefuroxim, begleitend symptomatische Therapie. Klinische Besserung, neurologischer Untersuchungsstatus unauffällig, Stirnschwellung komplett rückgebildet und rückläufige Entzündungsparameter (CRP $62 \mathrm{mg} / \mathrm{l}$ ), daher Entlassung nach Hause.

Verlauf. Nach 10 Tagen erneute Aufnahme bei wiederholter Stirnschwellung, Fieber und erneuten starken Kopfschmerzen. In der Bildgebung (MRT) zeigte sich eine ausgedehnte Sinusitis frontalis mit Durchbruch in den Schädel und Ausbildung mehrerer großer intrakranieller Empyeme. Bei bereits länger bestehendem Prozess zunächst Verzicht auf eine Empyemausräumung, und empirische Antibiotikatherapie mit Ceftriaxon, Metronidazol und Fosfomycin. Darunter rückläufige Entzündungsparameter, klinisch wenig Besserung. In der erneuten Bildgebung Zeichen eines Hirnödems und intrakranieller Empyemzunahme, daher neurochirurgische Sanierung des Befundes. Ein Erreger konnte nicht isoliert werden. Unter Fortführen der antibiotischen Therapie über 6 Wochen zunehmende Besserung. Im Verlauf kam es zur vollständigen Genesung ohne neurologisches Defizit.

Schlussfolgerung. Das hier beschriebene Krankheitsbild ist im angelsächsischen Raum unter dem Namen „pott's puffy tumor“ bekannt. Es ist eine seltene Erkrankung bestehend aus einer Sinusitis frontalis mit Osteomyelitis und assoziiertem subperiostalem Abszess. Eine gefürchtete Komplikation ist die Beteiligung intrakranieller Strukturen (wie z. B. Empyem). 
DGPI-PO-SI-5

Hämorrhagische Meningoenzephalitis durch Pneumokokken bei einem 4 Monate alten Säugling

\section{Sailer N.-L.', Eitel H.', Niethammer K. ${ }^{1}$, Longin A. ${ }^{2}$, Schmiedel G. ${ }^{1}$, von Schnakenburg $C .{ }^{1}$ \\ 'Klinik für Kinder und Jugendliche des Klinikums Esslingen, Esslingen, ${ }^{2}$ Klinik für Kinder und Jugendliche des Klinikums Esslingen, Kinderradio- logie, Esslingen}

Hintergrund. Schwere Pneumokokkeninfektionen sind seit Einführung der polyvalenten Impfstoffe selten geworden. Wir berichten von einer untypischen Verlaufsform mit einer rasch destruierenden Enzephalitis bei einem bis zur akuten Erkrankung gesunden Säugling, der 2-mal den 13-valenten Konjugatimpfstoff erhalten hatte.

Falldarstellung. Ein blasser, hypotoner, schreckhafter, fiebernder Säugling ohne neurologisches Defizit wurde eingewiesen. Nach Diagnostik therapierten wir i.v. antibiotisch sowie mit Aciclovir.

Laborwerte. 23\% Stabkernige, CrP 28,4 mg/l. Il-8 massiv erhöht 4112 pg/ $\mathrm{ml}$. Im Liquor 22 Zellen/ $\mu$ l. Liquor und Blutkultur: Strept. pneumoniae. Verlauf. Trotz zügiger Therapie verschlechterte sich der Zustand des Patienten mit fokalen Anfällen (auf Phenobarbital ansprechend), Halbseitensymptomatik rechts mit Fazialisparese, Anämie, Thrombozytopenie, Gerinnungsstörung, arterielle Hypotonie. Das cMRT zeigte ein zytotoxisches Ödem linkshemispärisch und eine Einblutung temporobasal bis hochfrontal mit Mittellinienverlagerung. Der Patient zeigte außer einer gespannten Fontanelle und dehiszenter Schädelnähte keine weiteren Symptome eines erhöhten Hirndrucks oder einer Einklemmung. Er erholte sich insgesamt überraschend gut. Bei Entlassung war er trotz handbetonter Hemiparese rechts wenig beeinträchtigt mit weiterer Besserung im Verlauf und blieb anfallsfrei unter einer niedrig dosierten Phenobarbitaltherapie.

Diskussion. Diese Verlaufsform einer hämorrhagischen Meningoenzephalitis als Komplikation einer Pneumokokkeninfektion ist selten. Das klassische Bild wäre eine sog. Haubenmeningitis, die hier nicht vorlag. Nachgewiesen wurde der im 13-valenten Konjugatimpfstoff nicht enthaltenen Serotyp 8, der nicht für diesen klinischen Verlauf typisch ist.

\section{DGPI-PO-SI-6}

\section{Unterschiedliche klinische Verlaufsformen in zwei Fällen von Malaria tropica}

Wöllner J.', Wilichowski E. ', Eiffert H. ${ }^{2}$, Gärtner J.'

'Universitätsmedizin Göttingen, Klinik für Kinder- und Jugendmedizin, Göttingen, ${ }^{2}$ Universitätsmedizin Göttingen, Institut für Medizinische Mikrobiologie, Göttingen

Hintergrund. Die Malaria ist die in Deutschland am häufigsten diagnostizierte Tropenerkrankung und kommt auch bei Kindern nicht selten vor. Die Mehrzahl der Fälle wird durch das Plasmodium falciparum, dem Erreger der Malaria tropica, verursacht. Abhängig vom klinischen Verlauf der Erkrankung wird eine unkomplizierte von einer komplizierten Malaria unterschieden. Patienten aus Hochrisikogebieten können rezidivierend an Malaria erkranken und eine Teilimmunität erwerben. Hierdurch sind mildere Verlaufsformen der Erkrankung möglich. Kasuistik. Wir berichten von zwei Fällen von Malaria tropica in unserer Klinik. Ein Patient stammte aus Nigeria und lebte erst wenige Wochen in Deutschland. Er zeigte einen ausgesprochen symptomarmen Verlauf mit nur einer spät auftretenden Fieberzacke. Eine zweite Patientin stammte aus Deutschland und erkrankte nach einer Uganda-Reise mit ausgeprägten Symptomen und typischem Fieberverlauf.

Schlussfolgerung. Die beiden Fälle veranschaulichen die sehr unterschiedlichen Verlaufsformen der Malaria tropica. Möglicherweise bedingte eine erworbene Teilimmunität bei dem afrikanischen Patienten den leichteren Erkrankungsverlauf. Bei entsprechender Anamnese sollte auch bei milden oder fehlenden typischen Symptomen, wie rezi- divierenden Fieberschüben, differenzialdiagnostisch an eine MalariaInfektion gedacht werden.

\section{DGPI-PO-SI-7 \\ Neonatale Coxsackie-B4-Infektion mit dem klinischen Bild einer neonatalen Hämochromatose}

Dresbach T. ${ }^{1}$, Eis-Hübinger A.-M. ${ }^{2}$, Schneider K. ${ }^{3}$, Schmitt J. ${ }^{3}$, Müller A. ${ }^{1}$ ${ }^{1}$ Universitätsklinikum Bonn, Neonatologie, Bonn, ${ }^{2}$ Universitätskliniken Bonn, Institut für Virologie, Bonn, ${ }^{3}$ St. Marien Hospital, GFO Kliniken Bonn, Neonatologie, Bonn

Kasuistik. Wir berichten über einen Patienten, der am 5. Lebenstag ein progredientes Leberversagen mit Hämolyse und disseminierter Koagulopathie entwickelte. Sonographisch zeigte sich eine Hepatomegalie und mäßig viel Aszites. Bei steigenden Leberenzymen, rasch progredienten Hämolysezeichen und beginnender disseminierter intravasaler Gerinnung erfolgte die Verlegung am 7. LT. in unsere Klinik. Bei Aufnahme zeigten sich deutlich erhöhte Werte der Transaminasen, Ferritin, CRP, IL-6 und Troponin-I.

Therapie und Verlauf. Bei Verdacht auf eine neonatale Hämochromatose erfolgten am Aufnahmetag eine Austauschtransfusion sowie eine Therapie mit Immunglobulinen, N-Acetylcystein, Selen und Desferroxamin. Die differenzialdiagnostisch eingeleiteten virologischen Untersuchungen konnten Coxsackie B4 in Blut, Trachealsekret, Urin und Stuhl nachweisen. Auch bei den Eltern, Geschwistern und den im Hause lebenden Angehörigen konnte Coxsackie $\mathrm{B}_{4}$ im Stuhl nachgewiesen werden. Unter symptomatischer Therapie normalisierten sich die Transaminasen bis zum 10. LT. Im Verlauf kam es zur Restitutio ad integrum. Schlussfolgerung. Die Ursachen für das neonatale Leberversagen umfassen neben Stoffwechseldefekten, die neonatale Hämachromatose und verschiedene Virusinfektionen. Bei unserem Patienten bestand zunächst der Verdacht auf eine neonatale Hämochromatose und wurde entsprechend der aktuellen Empfehlungen behandelt. Die weiteren Untersuchungen ergaben jedoch ein Leberversagen auf dem Boden einer Enterovirusinfektion. Vor allem der aus der Gattung der Enteroviren stammende Coxsackie-B-Virus kann in den ersten Tagen nach Geburt beim Neonaten zu generalisierten Infektionen mit Multiorganbeteiligung führen. Therapeutische Optionen bei neonatalen Enterovirusinfektionen sind begrenzt, Infektionen mit Multiorganbeteiligung enden oft letal.

\section{DGPI-PO-SI-8}

Eine seltene Differenzialdiagnose einer Kindesmisshandlung im frühen Säuglingsalter: desaströser Verlauf einer kongenitalen Herpes-simplex-Infektion mit Hydrozephalus und Ausbildung schwerer destruktiven Veränderungen im Hirnparenchym und beidseitiger Katarakt

\section{Yildiz I.', Seymour N.', Thuresson M. ${ }^{1}$}

${ }^{1}$ Friedrich-Ebert-Krankenhaus Neumünster, Klinik für Kinder- und Jugendmedizin, Neumünster

Kasuistik. Ein reifgeborener männlicher Säugling wurde erst im Alter von 5 Wochen für U2 dem Kinderarzt vorgestellt. Dabei fiel neben einem deutlich reduzierten AZ eine Gewichtsabnahme von $540 \mathrm{~g}$ seit Geburt, Hämatome im Stirnbereich, eine Bradykardie und ein Opisthotonus auf, so dass er mit V. a. eine Kindesmisshandlung in unsere Klinik eingewiesen wurde. Bei Aufnahme ungepflegter Zustand, Windelsoor. Rektale Körpertemperatur $33,8^{\circ} \mathrm{C}$. Gewicht 2320 g (1er P.), KU $37 \mathrm{~cm}$ (92er P.) und Länge $48 \mathrm{~cm}$ (4er P.). Weit offene Fontanelle, Sonnenuntergangsphänomen, weißliche Pupillen. Aufnahmelabor: CRP mit 1,4 mg/ dl leicht erhöht; $\mathrm{Ca}+2$ mit 3,51 mmol/1 und D-Dimere mit 3,64 mg/l erhöht. Diff-BB: 78\% Lympho- und 9\% Monozyten. Gerinnung inkl. Protein-C,-S, Faktor V unauffällig. Urin und Serum auf organische und Aminosäuren, Lactat, Pyruvat, Ammoniak, Acylcarnitin-Profil unauf- 
fällig. TORCH-Serologie: lediglich maternale HSV IgG Leihantikörper. Bei der Mutter Serum HSV IgG und IgM AK positiv.Im Liquor Lactat und Eiweiß initial leicht erhöht. Kindliche intrathekale Synthese HSV IgG AK im Verlauf. PCR auf CMV, VZV, Enteroviren, HSV im Serum und Liquor negativ. Zerebrale Bildgebung (Sono, cMRT-TOF und cCT): periventrikuläre Verkalkungen, enzephalomalazische Destruktion, Blutungen, Erweiterung der extrazerebralen Liquorräume und der Ventrikel, Aquäduktstenose. Ophthalmologisch bilaterale Katarakte. Humangenetik: Kein Hinweis auf ein Syndrom. Therapie: i.v. Aciclovir insgesamt für 3 Wochen. Anlage eines V-P-Shunts, Valproat-Therapie, Neurorehabilitation, Katarakt Extraktion bds.

Schlussfolgerung. Die typische Triade einer kongenitalen HSV-Infektion mit Haut-, Augen- und ZNS-Befunde wird nur bei weniger als einem Drittel der Fälle gesehen, dadurch kann die Diagnose kompliziert sein.

\section{DGPI-PO-SI-9}

\section{Enterovirus(EV)-Meningitis-Epidemie bei Kindern im östlichen Münsterland/Nordrhein-Westfalen}

\author{
Krüger C.' , Bär G. ', Sladeczek H.', Wild S.', Schuler-Lüttmann S. ', Bräucker \\ G. ${ }^{1}$
}

${ }^{1}$ St. Franziskus Hospital, Klinik für Kinder und Jugendliche, Ahlen, ${ }^{2}$ Universitätsklinikum Münster, Institut für Medizinische Mikrobiologie - Klin. Virologie, Münster

Fragestellung. EV-Infektionen treten gehäuft in den Sommermonaten auf und können schwere ZNS-Erkrankungen verursachen. Wir berichten über eine EV-Meningitis-Epidemie im Sommer 2013.

Methoden. Bei allen Kindern mit der Diagnose oder dem Verdacht auf eine Meningitis (Kopfschmerzen, Erbrechen, Fieber, Meningismus), die an der Kinderklinik des Kreises von Juni bis Oktober behandelt wurden, erfolgte eine EV-Diagnostik und -Typisierung im Rahmen des nationalen Surveillance-Programms aus Stuhl oder Liquor.

Ergebnisse. Bei 27 Kindern [14 weibl., Altersmedian: 7 Jahre 4 Monate (12 Tage bis 17 Jahre 5 Monate)] wurden 14 Echo3o-, 7 Echo11-, 2 Echo18und 1 CoxsackieA9-Infektion diagnostiziert (3 Isolate nicht typisierbar). Elf Infektionen traten im August, je 7 im Juli und September auf. Zwei Neugeborene (12+25 Tage; Echo3o, Echo11) hatten ein sepsisähnliches Bild, 2 Kinder (Echo11, Echo3o) eine Gastroenteritis, 23 Kinder eine Meningitis (Liquor-Zellzahl 19-1188/3; Eiweiß <50 mg/dl; Glukose normal). Alle Kinder erholten sich rasch, nur das Kind mit CoxsackieA9 entwickelte eine Myokarditis. In 3 Familien (2-mal 2 und 1-mal 3 Kinder) bestand ein zeitlicher und kausaler Zusammenhang (fast gleichzeitig erkrankt; innerhalb der Familie gleicher Serotyp). Ein direkter epidemiologischer Zusammenhang (zeitlich, räumlich, Serotyp) war nur bei 2 weiteren Kindern denkbar.

Schlussfolgerung. EV-Infektionen können zu einer lokalen Häufung von aseptischen Meningitiden führen, bei Neugeborenen zu einer Sepsis, die jedoch von verschiedenen zirkulierenden Serotypen verursacht werden. Ein direkter epidemiologischer Zusammenhang ließ sich nur innerhalb von Familien sichern; allerdings litt kein erwachsenes Familienmitglied an einer Meningitis. Asymptomatische Träger halten über einen langen Zeitraum die Transmission aufrecht.

\section{DGPI-PO-SI-10}

Meningitis-Kleinraumepidemie durch ECHO-Virus Typ 30 mit typischer Symptomatik und Verlauf bei teilweise fehlender Liquorpleiozytose bzw. mit minimaler Zellzahlerhöhung

\section{Pargac N.K.', Knötzsch A.', Kahleyss S.', Erbe B. ', Hildebrandt M. ', Heine A.'} 'Elblandklinikum Meißen, Klinik für Kinder- und Jugendmedizin, Meissen

Fragestellung. Virusmeningitiden kommen vor allem bei Kindern oder Patienten mit geschwächtem Immunsystem vor. ECHO-Viren sind eine Sonderform der Enteroviren und die klassischen Auslöser der Sommergrippe, können aber auch epidemische Hirnhautentzündungen auslösen. Typisch sind eine Nackensteifigkeit (Meningismus), ein allgemeines Krankheitsgefühl, Kopfschmerzen, Fieber, Erbrechen und Lichtscheue. Die Liquoruntersuchung vermag in der Regel die Virusmeningitis durch den Nachweis einer lymphozytär-mononukleären Pleiozytose (meist 25 x 500 Zellen $/ \mathrm{mm}^{3}$ ) zu sichern. Unsicherheiten bei der Diagnosestellung tauchen auf, wenn die erwartete Zellzahlerhöhung nicht gefunden wird. Meist wird von dann von Meningismus als Reizzustand gesprochen.

Patienten und Ergebnisse. In der Zeit vom 20.6.2013 bis 19.9.2013 wurden 49 Patienten (23 weibliche, 26 männliche) aus dem Landkreis Meißen im Alter von 2,5 bis 17 Jahren mit den Symptomen einer Meningitis stationär behandelt. Bei 48 Patienten war die Enterovirus-PCR positiv, in 39 Fällen war ECHO-Virus Typ 30, einmal Typ 5 nachweisbar. Der Liquoreinweißgehalt lag zwischen 140 und $828 \mathrm{mg} / \mathrm{L}$ (Durchschnitt: $331 \mathrm{mg} / \mathrm{L}$ ), die Zellzahl i.L. bei 2-749 Mpt/L (94 Mpt/L). 16 Patienten (33\%) hatten eine Zellzahl von $<25 \mathrm{Mpt} / \mathrm{l}$, von denen wiederum $10 \mathrm{~Pa}$ tienten Zellzahlen <10 Mpt/l (dabei 8-mal ECHO Typ 30) aufwiesen.

Diskussion. Die Verläufe aller Patienten erwiesen sich als gutartig und mild (ebenso bei mehreren Erwachsenen, die in unserer Neurologie im selben Zeitraum betreut wurden). Auch durch Einbeziehung des Gesundheitsamtes war es nicht möglich, den Krankheitsausbruch epidemiologisch näher zu charakterisieren. Ohne die PCR-Diagnostik wäre bei etlichen Patienten die Diagnose Virusmeningitis allein anhand des Pleiozytosenachweises nicht zu stellen gewesen.

\section{DGPI-PO-SI-11}

\section{Die Masern sind zurück}

Bertko E.', Gnodtke E. ', Borte M. ${ }^{1}$

'Klinikum St. Georg gGmbH, Klinik für Kinder- und Jugendmedizin, Leipzig

Fallbericht. Ein 16-jähriger Junge wird stationär aufgenommen mit seit dem Vortag bestehendem hohen Fieber, Gliederschmerzen, Erbrechen, Durchfall sowie vom Gesicht ausgehendem, auf Hals und Extremitäten ausbreitendem Exanthem. Vier Tage vorher bereits Temperaturen bis $40,3^{\circ} \mathrm{C}$ mit spontaner Entfieberung nach 2 Tagen. In der klinischen Untersuchung ausgeprägtes generalisiertes makulopapulöses, rot-livides Exanthem und Enanthem am Gaumen mit weißlichen Flecken an der Mundschleimhaut. Dabei deutliche Konjunktivitis beidseits mit Lichtscheu und zervikale Lympknotenschwellung. Laborchemische Untersuchungen (Masern-IgM positiv, Masern-RNA im Plasma nachgewiesen) bestätigten den klinischen Verdacht einer Maserninfektion. Therapie und Verlauf. Infusionstherapie sowie regelmäßige antipyretische und analgetische Therapie führten zu einer langsamen Besserung des Allgemeinbefindens. Kurze Zeit später musste der jüngere Bruder des Patienten ebenso wegen einer Maserninfektion stationär aufgenommen werden.

Schlussfolgerung. Nachdem im Jahr 2012 vergleichsweise wenig Masernfälle auftraten $(n=165)$, wurden im Jahr 2013 dem Robert-Koch-Institut 1721 Masernfälle übermittelt. Damit stieg die Inzidenz von o,2 auf 2,1 pro 100.000 Einwohner. Besonders betroffene Bundesländer waren Bayern und Berlin. Aber auch Bundesländer, in denen es bisher selten zu Masernausbrüchen kam (u. a. Sachsen, Sachsen-Anhalt), mussten im Jahr 2013 mehrere Masernfälle verzeichnen: Sachsen meldete 54, Sachsen-Anhalt 32 Fälle. Ein hoher Anteil der Maserninfektionen trat bei unzureichend immunisierten Jugendlichen und jungen Erwachsenen auf. 